\title{
Berberine protects against diet-induced obesity through regulating metabolic endotoxemia and gut hormone levels
}

\author{
JIAN HUI XU ${ }^{1,5^{*}}$, XING ZHEN LIU ${ }^{2,3^{*}}$, WEI PAN ${ }^{4}$ and DA JIN ZOU ${ }^{1}$ \\ ${ }^{1}$ Department of Endocrinology, Changhai Hospital, The Second Military Medical University, Shanghai 200433; \\ ${ }^{2}$ The Out-Patient Department, Hangzhou Sanatorium of Nanjing Military Command Region, Hangzhou, \\ Zhejiang 310007; ${ }^{3}$ Department of Rheumatology, Changhai Hospital; ${ }^{4}$ Department of Pathogen Biology, \\ The Second Military Medical University, Shanghai 200433, P.R. China
}

Received January 21, 2016; Accepted January 16, 2017

DOI: $10.3892 / \mathrm{mmr} .2017 .6321$

\begin{abstract}
Systemic inflammation, which can be induced by metabolic endotoxemia, and corresponding high-fat diet-mediated metabolic disorders are associated with gut microbiota. In the present study reverse transcription-polymerase chain reaction, immunofluorescence, pyrosequencing, ELISA and Oil Red O staining were performed to assess whether berberine can protect against diet-induced obesity, through modulating the gut microbiota and consequently improving metabolic endotoxemia and gastrointestinal hormone levels. Alterations in the gut microbiota induced by berberine resulted in a significant reduction in bacterial lipopolysaccharide levels in portal plasma. Levels of inflammatory and oxidative stress markers, as well as the mRNA expression levels of macrophage infiltration markers in visceral adipose tissue, were also reduced by berberine. Inhibition of the inflammatory response was associated with a reduction in intestinal permeability and an increase in the expression of tight junction proteins. In addition, berberine was reported to restore aberrant levels of gut hormones in the portal plasma, such as glucagon-like peptide-1 and -2, peptide YY, glucose-dependent insulinotropic polypeptide and pancreatic polypeptide. The present findings indicated that berberine, through modulating gut microbiota, restored the gut barrier, reduced metabolic endotoxemia and systemic inflammation, and improved gut peptide levels in high-fat diet-fed rats. The present study suggests that berberine
\end{abstract}

Correspondence to: Professor Da Jin Zou, Department of Endocrinology, Changhai Hospital, The Second Military Medical University, 800 Xiangyin Road, Shanghai 200433, P.R. China

E-mail: zwjd22@medmail.com.cn

Present address: ${ }^{5}$ The Out-Patient Department, 73171 Hospital of PLA, Nanjing Military Command Region, Shanghai 200433, P.R. China

*Contributed equally

Key words: berberine, gut microbiota, endotoxemia, visceral adipose tissue, gut peptides may be an effective therapeutic strategy for the treatment of obesity and insulin resistance.

\section{Introduction}

Berberine, which is an alkaloid extracted from Rhizoma coptidis, has been traditionally used in Chinese medicine to treat gastrointestinal infections, due to its antimicrobial properties. Previous clinical research and animal studies have demonstrated that berberine can regulate glucose and lipid metabolism, and attenuate insulin resistance (1-3). Several mechanisms have been proposed to explain the actions of berberine in in vitro and in vivo models; these include: The activation of AMP-activated protein kinase to downregulate the expression of lipogenesis genes and upregulate the expression of energy expenditure genes (4); the inhibition of intestinal disaccharidases and $\alpha$-glucosidase $(5,6)$; the upregulation of the hepatic low-density lipoprotein receptor (7); the inhibition of intestinal cholesterol absorption (8); and increased intestinal glucagon-like peptide-1 (GLP-1) secretion $(9,10)$. Since berberine has been reported to have poor intestinal absorption and very low absolute bioavailability, with values ranging between 0.36 and $0.68 \%$ in rats, it may be hypothesized that berberine exerts its effects in the intestinal tract prior to its absorption $(11,12)$.

Accumulating evidence suggests that the gut microbiome serves an important role in obesity and related metabolic abnormalities. Taking into consideration the antibacterial activity of berberine, modulation of the gut microbiota has been suggested as another possible mechanism for its actions. Xie et al (2) reported that berberine significantly increased the intestinal expression of fasting-induced adipose factor (Fiaf), which acts as a lipoprotein lipase inhibitor, thereby inhibiting triglyceride deposition in adipocytes. Furthermore, it has been reported that Lactobacillus paracasei may upregulate Fiaf expression in colonic epithelial cells (13). These findings indicate that, through modulating the gut microbiota, berberine may increase the expression of Fiaf.

The leakage of bacterial-derived lipopolysaccharide (LPS) through the damaged intestinal mucosa into the circulation is a well-established mechanism of metabolic endotoxemia that can trigger systemic inflammation. Zhang et al (14) previously 
reported that berberine may prevent obesity and insulin resistance in high-fat diet (HFD)-fed rats by modulating the gut microbiota, thus contributing to the alleviaton of inflammation via a reduction in serum LPS-binding protein and monocyte chemotactic protein-1 (MCP-1). However, there is currently little information available on whether berberine can modulate endotoxemia and intestinal or systemic inflammation.

Previous studies have suggested that gut microbiota may contribute to the development of obesity and related disorders by modulating the synthesis of enteroendocrine peptides involved in glucose and energy homeostasis. A series of studies by Cani et al (15-18) reported that prebiotic use can interfere with plasma levels of intestinal peptides, causing an increase in GLP-1, GLP-2 and peptide YY (PYY), and a decrease in gastric inhibitory polypeptide (GIP) in rodent and human subjects. Short-chain fatty acids (SCFAs), produced during the bacterial fermentation of non-digestible carbohydrates, have been shown to promote GLP-1 and PYY secretion by stimulating the expression of $\mathrm{G}$ protein-coupled receptor 41 and 43 in enteroendocrine cells (L-cells) (19-22). Furthermore, prebiotics have been reported to promote GLP-2 production by increasing the number of intestinal L-cells and the mRNA expression of proglucagon (15). Taken together, these studies suggest that the fermentation of prebiotics by intestinal bacteria can interfere with gut peptide production. In addition, previous studies have revealed that berberine can increase the number of intestinal L-cells and thereby increase plasma GLP-1 levels in normal and diabetic rats $(9,10,23)$. Furthermore, berberine has been demonstrated to promote ileal GLP-2 secretion and thus decrease LPS plasma levels in diabetic rats (24). Since GLP-2 is known to regulate the proliferation of intestinal epithelial cells and thus the integrity of the gut barrier, berberine may also promote intestinal integrity through modulating GLP-2 levels. Although previous studies have suggested that the effects of berberine on glucose metabolism and energy homeostasis are related to its modulatory effects on gut hormones, it remains to be elucidated whether other hormones may also be involved.

In order to investigate the effects of berberine administration on the gut and the gut microbiome, the present study employed a rat model of diet-induced obesity. Alterations in gut microbiota were assessed using 454 pyrosequencing, whereas intestinal hormone levels were assessed using Luminex technology. Intestinal permeability, the expression of tight junction proteins, endotoxemia, and systemic inflammation were also investigated.

\section{Materials and methods}

Materials. Berberine and fluorescein isothiocyanate (FITC)-dextran were purchased from Merck KGaA (Darmstadt, Germany). All diets were purchased from Research Diets, Inc. (New Brunswick, NJ, USA). Rat metabolic hormone kit, GLP-1 (cat. no. EGLP-35K) and GLP-2 (cat. no. EZGLP2-37K) ELISA kits were purchased from Merck KGaA. TRIzol ${ }^{\circledR}$ reagent and DAPI were purchased from Invitrogen (Thermo Fisher Scientific, Inc., Waltham, MA, USA). Reverse transcription kit and SYBR-Green were purchased from Takara Biotechnology Co., Ltd. (Dalian, China). Optimal cutting temperature (OCT) compound was purchased from Sakura Finetek USA, Inc. (Torrance, CA, USA). Claudin1 (cat. no. ab203563), claudin2 (cat. no. ab53032) and GLP-1 antibodies (cat. no. ab22625) were purchased from Abcam (Cambridge, MA, USA). Goat anti-rabbit Cy3-conjugated secondary antibody (cat. no. 111-165-003) was purchased from Jackson ImmunoResearch Laboratories, Inc. (West Grove, PA, USA). QIAamp DNA stool minikit was purchased from Qiagen, Inc. (Valencia, CA, USA). FastPfu polymerase was purchased from TransGen Biotech Co., Ltd. (Beijing, China). Axy-Prep DNA Gel Extraction kit was purchased from Axygen Biotechnology Co., Ltd. (Taizhou, China).

Animals. Thirty male Sprague-Dawley rats (age, 6 to 8 weeks; weight, $260 \mathrm{~g}$ ) were purchased from the SLAC Laboratory Animal Co., Ltd. (Shanghai, China), and were housed in a controlled environment $\left(21\right.$ to $25^{\circ} \mathrm{C}$; inverted 12 -h daylight cycle; lights-off at 6:00 p.m.) in groups of 2 rats/cage and given free access to water and food. Following an acclimation period of 1 week, the rats were fed a control diet (Ctl group; $n=10$, $10 \%$ kcal from fat) or a HFD (HF group; $n=20,45 \%$ kcal from fat) for 14 weeks. Following 14 weeks, 10 rats from the HF group were maintained on the HFD however, they were given an oral supplement of berberine $(150 \mathrm{mg} / \mathrm{kg} /$ day $)$ for 6 weeks (HB group). For the duration of the study, the animals were weighed once a week, and their food intake was measured twice a week. All experimental procedures were validated by the Ethics Committee of Changhai Hospital, The Second Military Medical University (Shanghai, China).

Oral glucose tolerance test. The glucose tolerance tests were conducted following 6 weeks of berberine administration. Following a $12 \mathrm{~h}$ fast, the rats received an oral load of $50 \%$ glucose solution $(2.0 \mathrm{~g} / \mathrm{kg})$. Blood glucose was sampled in the tail vein before and 15, 30, 60, 90 and 120 min following glucose administration with an ACCU-CHEK glucose meter (Roche Diagnostics, Basel, Switzerland).

In vivo intestinal permeability. Rats from all groups were fasted for $6 \mathrm{~h}$ and were subsequently administered FITC-dextran diluted in saline by gavage $(500 \mathrm{mg} / \mathrm{kg}, 125 \mathrm{mg} / \mathrm{ml})$. Following 1 and $4 \mathrm{~h}, 500 \mu \mathrm{l}$ of blood was sampled from the tail vein, placed in ice-cold heparinized tubes and centrifuged $(12,000 \mathrm{x} g$ for 3 min at $\left.4^{\circ} \mathrm{C}\right)$. The obtained plasma was then diluted with PBS $(1: 3 \mathrm{v} / \mathrm{v})$ and the FITC-dextran concentration was determined using a fluorescence spectrophotometer (F7000; Hitachi, Ltd., Tokyo, Japan) at an excitation wavelength of $485 \mathrm{~nm}$ and an emission wavelength of $535 \mathrm{~nm}$. A standard curve was obtained by diluting serial concentrations of FITC-dextran in non-treated plasma diluted with PBS (1:3 v/v).

Blood samples. At the end of the experiments, the rats were anesthetized by an intraperitoneal injection of $30 \mathrm{mg} / \mathrm{kg}$ pentobarbital following a 12-h fasting period. Blood samples were collected from the orbital plexus and the hepatic portal vein and centrifuged $\left(2,000 \times \mathrm{g}\right.$ for $10 \mathrm{~min}$ at $\left.4^{\circ} \mathrm{C}\right)$ to obtain plasma for further biochemical analyses. LPS concentration in portal plasma was determined using a kit utilizing Tachypleus amebocyte lysate (Endosafe; Charles River Laboratories International, Inc., Wilmington, MA, USA) and 
Table I. Primer sequences used for reverse transcription-quantitative polymerase chain reaction.

\begin{tabular}{lll}
\hline Gene & \multicolumn{1}{c}{ Forward primers $\left(5^{\prime} \rightarrow 3^{\prime}\right)$} & \multicolumn{1}{c}{ Reverse primers $\left(5^{\prime} \rightarrow 3^{\prime}\right)$} \\
\hline TNF- $\alpha$ & TACTGAACTTCGGGGTGATTGGTCC & CAGCCTTGTCCCTTGAAGAGAACC \\
IL-1 $\beta$ & GCTGTGGCAGCTACCTATGTCTTG & AGGTCGTCATCATCCCACGAG \\
PAI- 1 & AGTCTTTCCGACCAAGAGCA & CCAGTTTGTCCCAAAGGAA \\
NADPHox & AAGTCATCCCCGCAACTGTTC & CCCGCTTCCTCATCTGCAATTC \\
STAMP-2 & ATCCCATCAAAATTTGGCTT & CGCTGTGATTTGGAAGATTTAATAC \\
MCP-1 & CAGATGCAGTTAATGCCCCAC & AGCCGACTCATTGGGATCAT \\
F4/80 & CAGCTGTCTTCCCGACTTTC & TAATCAAGATTCCGGCCTTG \\
claudin-1 & GCTGTCATCGGGGGCATAATA -2 & CCTGGCATTGATAGGGGTCAT \\
occludin & GGACACTTATCAAGCGAG & CAGCAATGGGATTTAGACT \\
ZO-1 & CCTCTGACCTTGTCCGTGGATG & TCCCTGCTTTCCCCTTCGTG \\
proglucogan & CTACCTTATTGAATGTC & AACTGAATGGTCTGATGCT \\
GAPDH & CCTCTATGCCAACACAGT & AGCCACCAATCCACACAG \\
\hline
\end{tabular}

TNF, tumor necrosis factor; IL, interleukin; PAI-1, plasminogen activator inhibitor-1; NADPHox, nicotinamide-adenine dinucleotide phosphate oxidase; STAMP-2, six transmembrane protein of prostate-2; MCP-1, monocyte chemotactic protein-1; F4/80, EGF-like module-containing mucin-like hormone receptor-like 1; ZO-1, zonula occludens-1.

estimated using the kinetic turbidimetric method. Intestinal hormone levels in portal plasma [total GIP, total pancreatic polypeptide (PP) and PYY] were determined in triplicate using a rat metabolic hormone kit (cat. no. RMHMAG-84K; Merck KGaA) and Luminex technology (Bio-Plex Multiplex system; Bio-Rad Laboratories, Inc., Hercules, CA, USA) according to the manufacturer's protocol. Total portal GLP-1 and GLP-2 levels were determined using ELISA kits. Plasma alanine triglycerides, cholesterol aminotransferase (ALT) and aspartate aminotransferase (AST) were determined using an automatic biochemistry analyser (HITACHI 2000; Hitachi, Ltd.).

Tissue samples. The rats were anesthetized using chloral hydrate $(400 \mathrm{mg} / \mathrm{kg})$ and sacrificed by cervical dislocation. The visceral adipose tissue, and segments of the liver and proximal colon, were then removed. Tissues were immediately immersed in liquid nitrogen and stored at $-80^{\circ} \mathrm{C}$ for further mRNA analysis. The remaining liver samples were used for hepatic lipid analysis and were stained with Oil Red $\mathrm{O}$ to detect fat droplets. The proximal colon samples were used for further immunofluorescence analysis.

Reverse transcription quantitative polymerase chain reaction $(R T-q P C R)$. Total RNA was extracted form tissue samples using TRIzol ${ }^{\circledR}$ reagent according to the manufacturer's protocol. Total RNA $(1 \mu \mathrm{g})$ was reverse transcribed into cDNA using the PrimeScript RT reagents kit (Takara Biotechnology Co., Ltd.). Briefly, the sample was incubated at $37^{\circ} \mathrm{C}$ for $15 \mathrm{~min}$ and then at $85^{\circ} \mathrm{C}$ for $5 \mathrm{sec}$. The mRNA levels of the different genes were examined using RT-qPCR. qPCR was conducted using the Rotor-Gene 3000 system and software (Qiagen, Inc., Valencia, CA, USA) using SYBR-Green. The thermocycling conditions were as follows: $95^{\circ} \mathrm{C}$ for $2 \mathrm{~min}$, followed by 40 cycles of $95^{\circ} \mathrm{C}$ for $10 \mathrm{sec}, 55^{\circ} \mathrm{C}$ for $30 \mathrm{sec}$ and $72^{\circ} \mathrm{C}$ for $30 \mathrm{sec}$. The primer sequences for the targeted genes are presented in Table I. The relative expression of each gene was normalized to the expression of the GAPDH gene and was calculated using the comparative $\mathrm{Cq}$ method $(\Delta \Delta \mathrm{Cq})(25)$.

Oil Red $O$ staining. Hepatic fat accumulation was evaluated by Oil Red O staining. Liver tissue was embedded in OCT compound and frozen in liquid nitrogen. The tissue was sliced into $8-\mu \mathrm{m}$ cryostat sections and stained with $0.05 \%$ Oil Red $\mathrm{O}$ at room temperature for $30 \mathrm{~min}$ to detect lipid droplets. Photomicrographs were taken with a Nikon Eclipse E600 microscope (Nikon Corporation, Tokyo, Japan). The percentage of positively stained Oil Red $\mathrm{O}$ areas was quantified using the Image-Pro Plus software (version 6; Media Cybernetics, Inc., Rockville, MD, USA).

Immunofluorescence. Segments of the proximal colon were removed, washed with PBS and fixed immediately in $4 \%$ paraformaldehyde. The fixed tissue was dehydrated in ethanol, cleared in xylene, and embedded in paraffin. The paraffin sections $(4-\mu \mathrm{m})$ were deparaffinized, rehydrated, treated with EDTA antigen retrieval buffers for $25 \mathrm{~min}$ at $4^{\circ} \mathrm{C}$, and incubated with $5 \%$ bovine serum albumin (Sangon Biotech Co., Ltd., Shanghai, China) for 20 min to block non-specific binding. The slides were incubated with rabbit anti-claudin-1 (dilution, 1:300) or rabbit anti-claudin-2 primary antibodies (dilution, 1:300) overnight at $4^{\circ} \mathrm{C}$ in a moist chamber. The number of L-cells was determined by staining with rabbit anti-GLP-1 primary antibody (dilution, 1:300) overnight at $4^{\circ} \mathrm{C}$. Subsequently, slides were washed 3 times with PBS and incubated with goat anti-rabbit $\mathrm{Cy} 3$-conjugated secondary antibody (dilution, 1:100) for $50 \mathrm{~min}$ at room temperature. The slides were washed a further 3 times with PBS, mounted 

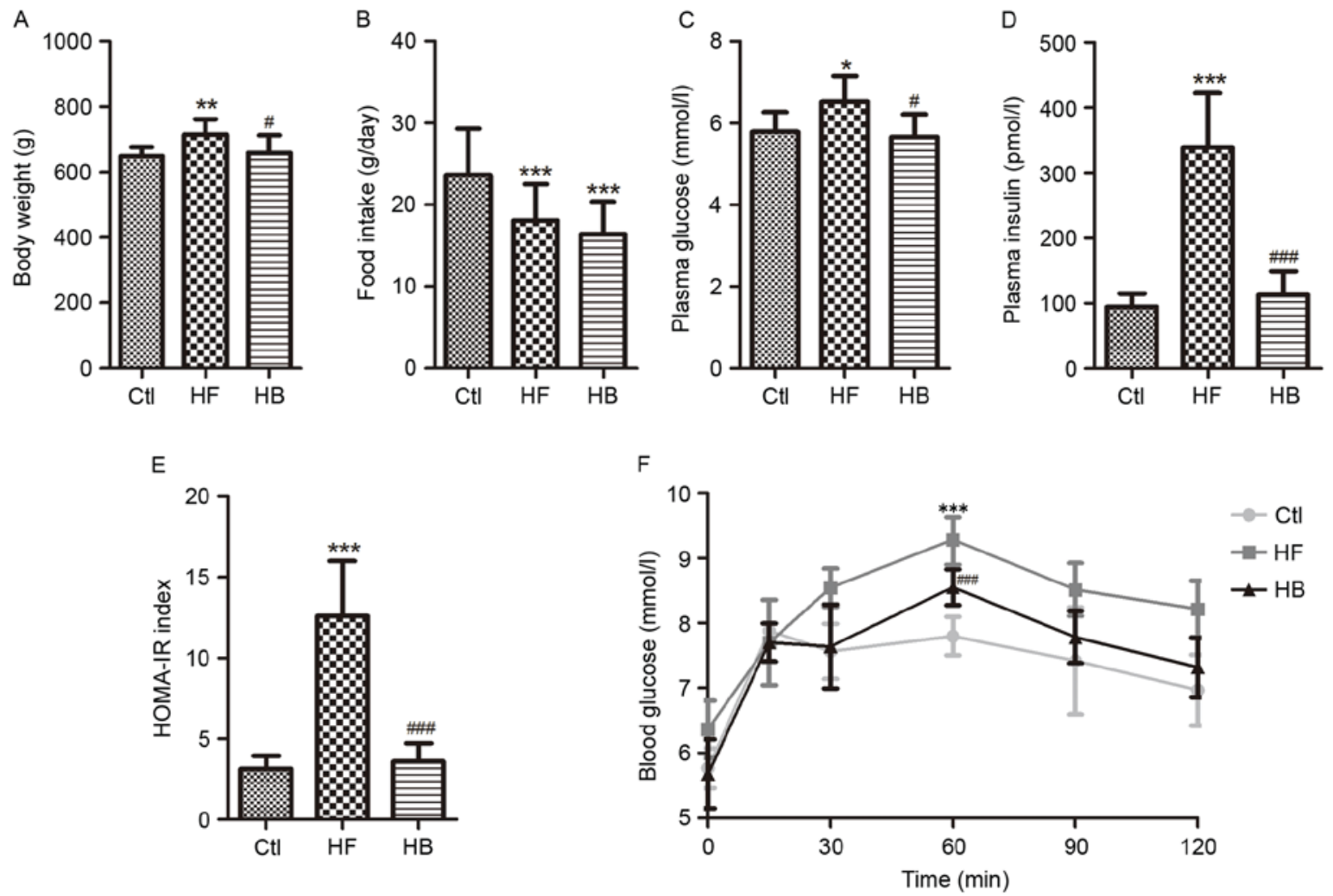

Figure 1. Berberine reduced weight gain and improved glucose homeostasis in HFD-fed rats. (A) Body weight. (B) Daily food intake per rat. (C) Fasting plasma glucose concentration. (D) Fasting plasma insulin concentration. (E) HOMA-IR index, calculated using the following equation: FBG (mmol/l) $x$ FINS (mU/l)/22.5. (F) Oral glucose tolerance test. Data are expressed as the mean \pm standard deviation. ${ }^{*} \mathrm{P}<0.05,{ }^{* * *} \mathrm{P}<0.01,{ }^{* * * *} \mathrm{P}<0.001 \mathrm{compared}$ with the $\mathrm{Ct}$ group; ${ }^{~} \mathrm{P}<0.05,{ }^{\# \# \#} \mathrm{P}<0.001$ compared with the HF group. Ctl, normal diet; HF, HFD; HB, HFD supplemented with berberine for 6 weeks; HFD, high-fat diet; HOMA-IR, homeostasis model assessment of insulin resistance; FBG, fasting blood glucose; FINS, fasting blood insulin; OGTT, oral glucose tolerance test.
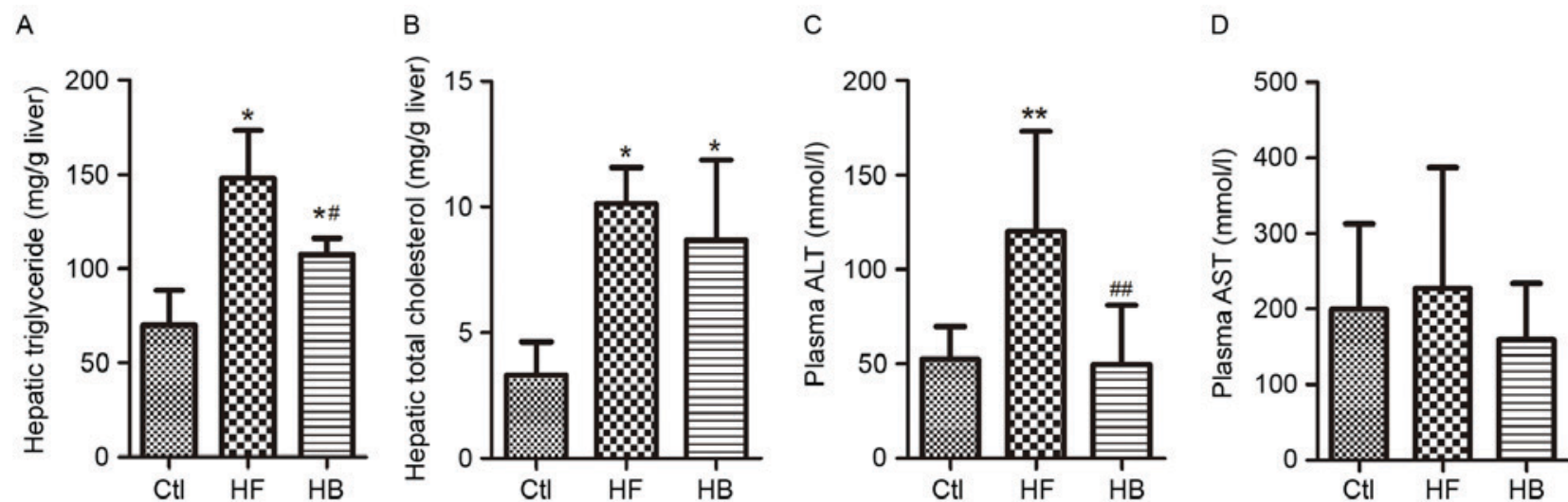

E

Ctl

$\mathrm{HF}$

$\mathrm{HB}$

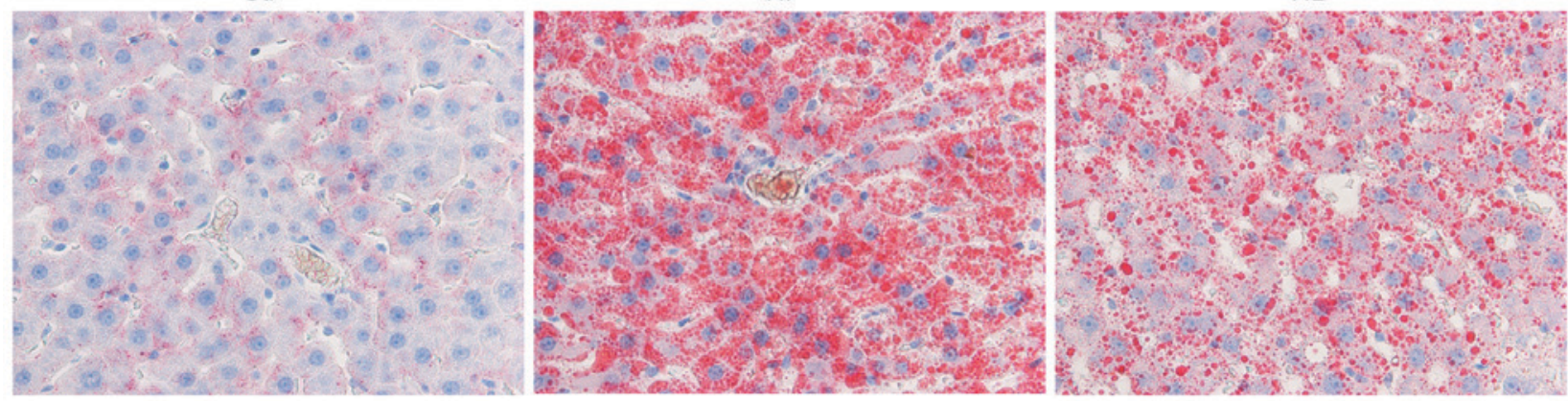

Figure 2. Berberine attenuated HFD-induced hepatic injury and hepatic steatosis. (A) Hepatic triglyceride content. (B) Hepatic total cholesterol content. (C) ALT plasma concentration. (D) AST plasma concentration. (E) Fresh-frozen liver sections were stained with Oil Red O (magnification, x100). Data are expressed as the mean \pm standard deviation. ${ }^{*} \mathrm{P}<0.05$, ${ }^{* *} \mathrm{P}<0.01$ compared with the $\mathrm{Ctl}$ group; ${ }^{\prime} \mathrm{P}<0.05,{ }^{\# \prime} \mathrm{P}<0.01$ compared with the HF group. Ctl, normal diet; HF, HFD; HB, HFD supplemented with berberine for 6 weeks; HFD, high-fat diet; ALT, alanine aminotransferase; AST, aspartate aminotransferase. 
with ProLong Gold antifade reagent with DAPI, and analyzed under a Nikon Eclipse TE-2000-U fluorescent microscope (Nikon Corporation). A total of 5 fields from each intestinal segment were selected, and the mucosal area was manually delineated and measured by an image analyzer (Motic Image Plus 2.0ML; Motic Incorporation, Ltd., Causeway Bay, Hong Kong) for determining the number of L-cells. All stained samples were analyzed in a double-blind manner by 2 experienced investigators.

\section{Pyrosequencing}

DNA extraction from fecal samples. Cecal feces were collected from the caecum of each rat whilst under abdominal anaesthesia $(30 \mathrm{mg} / \mathrm{kg}$ sodium pentobarbital) and were stored at $-80^{\circ} \mathrm{C}$ prior to analysis. The total bacterial genomic DNA was extracted from the frozen feces $(200 \mathrm{mg})$ using the QIAamp DNA stool minikit according to the manufacturer's protocol.

PCR amplification of $16 S$ rRNA and pyrosequencing. The extracted DNA served as a template to amplify the V1-3 region of the 16S rRNA gene. The primers used were as follows: Forward primer 5'-NNNNNNNNAGAGTTTGATCCTGGC TCAG-3' and reverse primer 5'-NNNNNNNNTTACCGC GGCTGCTGGCAC-3'. NNNNNNNN indicates the 8-base bar code sequence used to tag each PCR product, and the underlined sequence indicates the broad-range primers used to amplify the V1-3 region of the 16S rRNA gene. The PCR amplification mixture $(20 \mu \mathrm{l})$ contained $10 \mathrm{ng}$ template DNA, $4 \mu 1$ 5X PCR FastPfu buffer, 0.2 units FastPfu polymerase, $2.5 \mathrm{mM}$ dNTP mixture and $0.4 \mu \mathrm{M}$ of each primer. The PCR reactions were performed using a GeneAmp PCR system 9700 cycler (Applied Biosystems; Thermo Fisher Scientific, Inc.). The PCR conditions were as follows: Denaturation at $95^{\circ} \mathrm{C}$ for $2 \mathrm{~min}$, followed by 25 cycles at $95^{\circ} \mathrm{C}$ for $30 \mathrm{sec}, 55^{\circ} \mathrm{C}$ for $30 \mathrm{sec}$ and $72^{\circ} \mathrm{C}$ for $30 \mathrm{sec}$, and a final extension at $72^{\circ} \mathrm{C}$ for $5 \mathrm{~min}$. The PCR products were separated by electrophoresis and subsequently cut from the $2 \%$ agarose gel. The products were purified using the Axy-Prep DNA Gel Extraction kit. The purified DNA was quantified using the QuantiFluor system (Promega Corporation, Madison, WI, USA). A total of $4 \mu \mathrm{g}$ purified DNA was added to a master pool, and the DNA pool was sent to Major Biosystem Co., Ltd., (Taipei, Taiwan) for pyrosequencing using the GS FLX system (Roche Diagnostics $\mathrm{GmbH}$, Mannheim, Germany) according to the manufacturer's protocol. The company analysed the data using Weighted UniFrac principal coordinates analysis (PCoA), principal component analysis (PCA), redundancy analysis (RDA), Monte Carlo permutation and Mothur tests.

Statistical analysis. Experiments were repeated at least 3 times and data are expressed as the mean \pm standard deviation. $\mathrm{P}<0.05$ was considered to indicate a statistically significant difference. The statistical significance of the difference between groups was assessed by one-way analysis of variance, followed by a post hoc Bonferroni's multiple comparison tests; or by Kruskal-Wallis test for non-parametric data, followed by a Dunn's multiple comparison test. Correlations between parameters were assessed by the Spearman's correlation coefficent. The analysis was performed using SPSS software version 16.0 (SPSS, Inc., Chicago, IL, USA) and figures were created using GraphPad Prism 5.0 (GraphPad Software, Inc., La Jolla, CA, USA).

\section{Results}

Berberine prevents obesity and improves glucose homeostasis in HFD-fed rats. Rats maintained on a HFD for 14 weeks exhibited a significant increase in body weight compared with the control rats $(636.26 \pm 44.83$ vs. $591.34 \pm 30.65 \mathrm{~g} ; \mathrm{P}<0.01$; Fig. 1A). Treatment with berberine for 6 weeks significantly reversed the body weight increase of HFD-fed rats compared with untreated HFD-fed rats $(658.58 \pm 54.04$ vs. $715.59 \pm 46.70 \mathrm{~g}$; $\mathrm{P}<0.05$; Fig. 1A). As a result, rats in the HB treatment group had a body weight similar to the control group (Fig. 1A). During the course of the study, food intake was monitored twice a week. Average daily food intake appeared to be smaller in the HB treatment group; however, no significant difference was revealed when compared with the HF group (Fig. 1B). These results suggested that berberine may prevent obesity without interfering with food intake.

Fasting blood glucose and fasting blood insulin appeared to be significantly increased in rats of the HF group compared with the control group (Fig. 1C and D). The HFD also caused impaired glucose tolerance and insulin resistance, which was apparent by the significantly increased homeostatic model assessment of insulin resistance index and the significantly increased area under the curve following glucose challenge (Fig. 1E and F). Berberine treatment significantly improved fasting blood insulin and insulin resistance, however, not fasting blood glucose (Fig. 1C-F).

Berberine alleviates HFD-induced hepatic steatosis and injury. Hepatic steatosis was evaluated by measuring hepatic triglyceride contents via Oil Red O staining, whereas hepatic injury was evaluated by measuring circulating liver enzyme levels. Rats maintained on a HFD developed hepatic steatosis and injury, as reflected by the significantly increased hepatic triglyceride contents and ALT levels (Fig. 2A-D). Furthermore, Oil Red O staining demonstrated that large lipid droplets accumulated in the liver of HFD-fed rats (Fig. 2E). Berberine supplementation significantly decreased plasma ALT levels however, it did not affect aspartate aminotransferase levels when compared with untreated HFD-fed rats (Fig. 2C and D). A marked decrease in the amount of Oil Red O-stained lipid droplets in the berberine-treated group was also observed (Fig. 2E). These results suggested that HFD-induced hepatic steatosis and injury may be significantly alleviated by berberine.

Berberine reduces endotoxemia and visceral adipose tissue inflammation in HFD-fed rats. LPS levels in portal plasma were significantly higher in HFD-fed rats compared with control rats (Fig. 3A). Following treatment with berberine for 6 weeks, LPS plasma levels in HFD-fed rats were significantly reduced when compared with the untreated HFD-fed rats; however, LPS levels in berberine-treated rats remained higher than in control rats. With regards to inflammation and oxidative stress in visceral adipose tissue, and their role in obesity and insulin resistance, the following seven genes were investigated: Tumor necrosis factor- $\alpha$ (TNF- $\alpha)$, interleukin-1 $\beta$ (IL-1 $\beta$ ), 


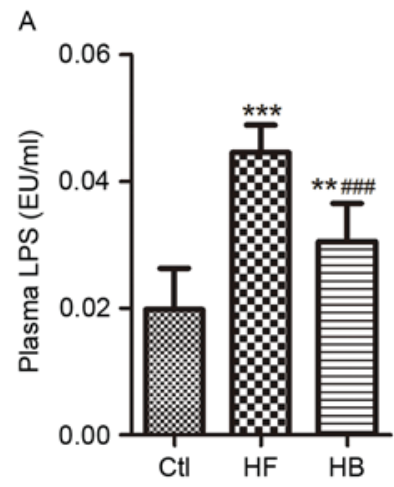

B

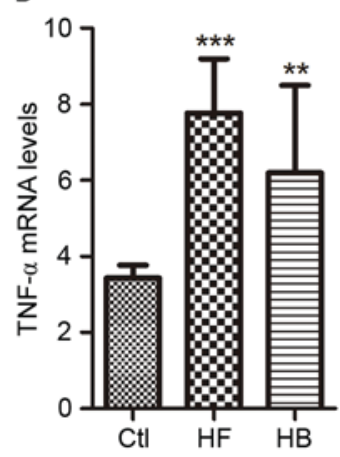

E

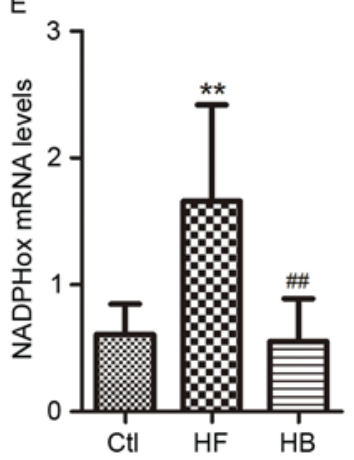

F

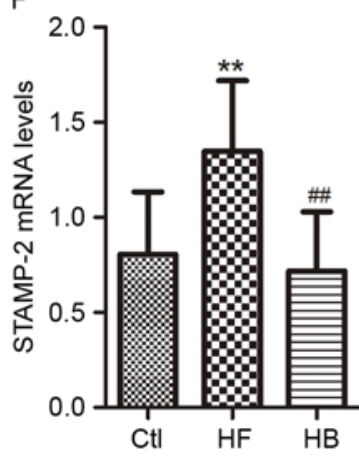

C

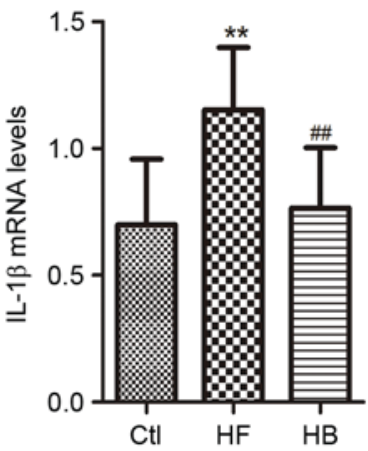

G

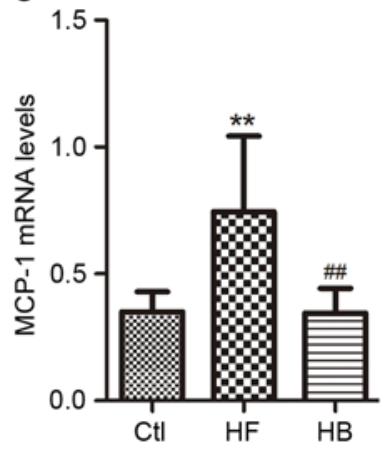

D

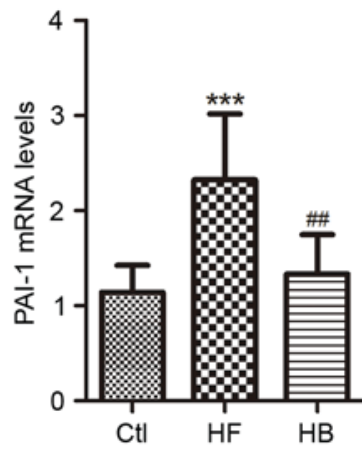

$\mathrm{H}$

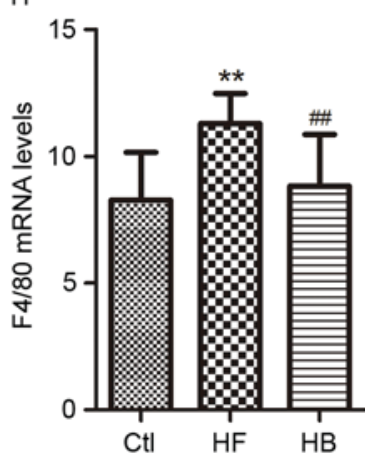

Figure 3. Berberine reduced endotoxemia and visceral adipose tissue inflammation in HFD-fed rats. (A) Portal plasma LPS concentrations. (B) TNF- $\alpha$ mRNA expression levels. (C) IL-1 $\beta$ mRNA expression levels. (D) PAI-1 mRNA expression levels. (E) NADPHox mRNA expression levels. (F) STAMP-2 mRNA expression levels. (G) MCP-1 mRNA expression levels. (H) F4/80 mRNA expression levels. Data are expressed as the mean \pm standard deviation. ${ }^{* *} \mathrm{P}<0.01$, ${ }^{* * *} \mathrm{P}<0.001$ compared with the Ctl group; ${ }^{\# \#} \mathrm{P}<0.01,{ }^{\# \# \#} \mathrm{P}<0.001$ compared with the HF group. Ctl, normal diet; HF, HFD; HB, HFD supplemented with berberine for 6 weeks; HFD, high-fat diet; LPS, lipopolysaccharide; EU, endotoxin unit; TNF, tumor necrosis factor; IL, interleukin; PAI-1, plasminogen activator inhibitor-1; NADPHox, nicotinamide-adenine dinucleotide phosphate oxidase; STAMP-2, six transmembrane protein of prostate-2; MCP-1, monocyte chemotactic protein-1; F4/80, EGF-like module-containing mucin-like hormone receptor-like 1.
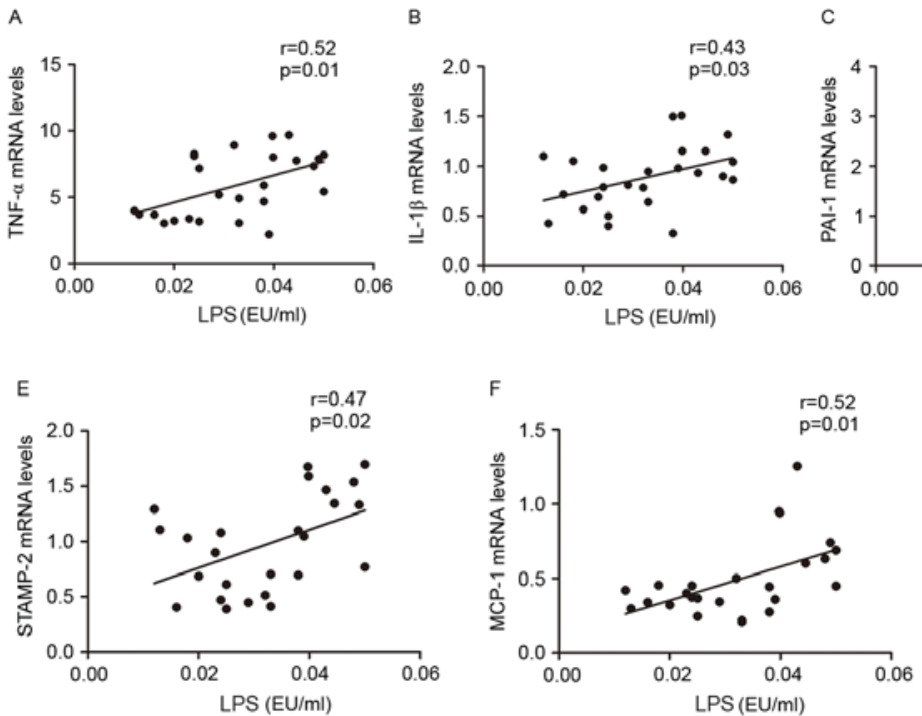
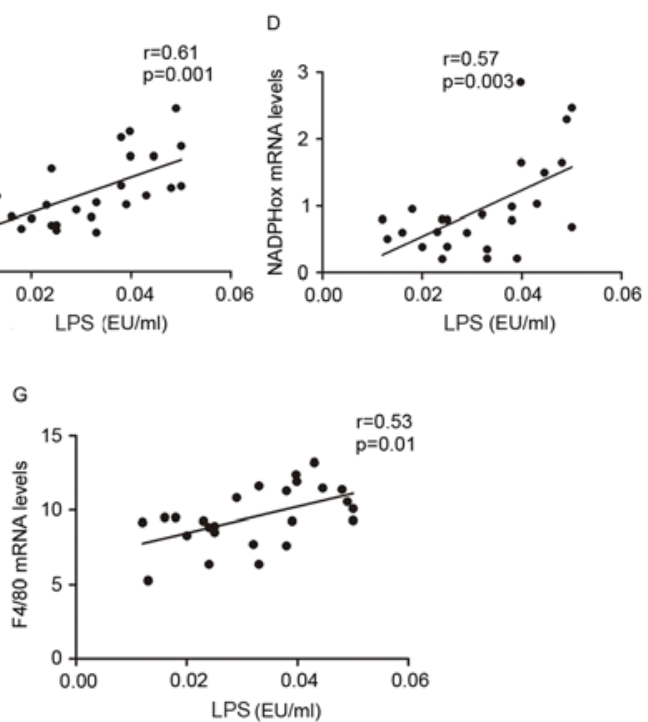

Figure 4. Metabolic endotoxemia was positively correlated with inflammation, oxidative stress and macrophage infiltration markers. Correlation between: Portal plasma LPS level and (A) TNF- $\alpha$, (B) IL-1 $\beta$, (C) PAI-1, (D) NADPHox, (E) STAMP-2, (F) MCP-1 and (G) F4/80 mRNA levels in visceral adipose tissue of Ctl, HF and HB rats. The inset corresponds to Pearson's correlation and corresponding P-value. Ctl, normal diet; HF, HFD; HB, HFD supplemented with berberine for 6 weeks; HFD, high-fat diet; LPS, lipopolysaccharide; TNF, tumor necrosis factor; IL, interleukin; PAI-1, plasminogen activator inhibitor-1; NADPHox, nicotinamide-adenine dinucleotide phosphate oxidase; STAMP-2, six transmembrane protein of prostate-2; MCP-1, monocyte chemotactic protein-1; F4/80, EGF-like module-containing mucin-like hormone receptor-like 1; EU, endotoxin unit.

plasminogen activator inhibitor-1 (PAI-1), six transmembrane protein of prostate-2 (STAMP-2), nicotinamide-adenine dinucleotide phosphate oxidase (NADPHox), MCP-1 and EGF-like module-containing mucin-like hormone receptor-like 1 (F4/80). In visceral adipose tissue samples, the mRNA expression levels of these genes were significantly increased 

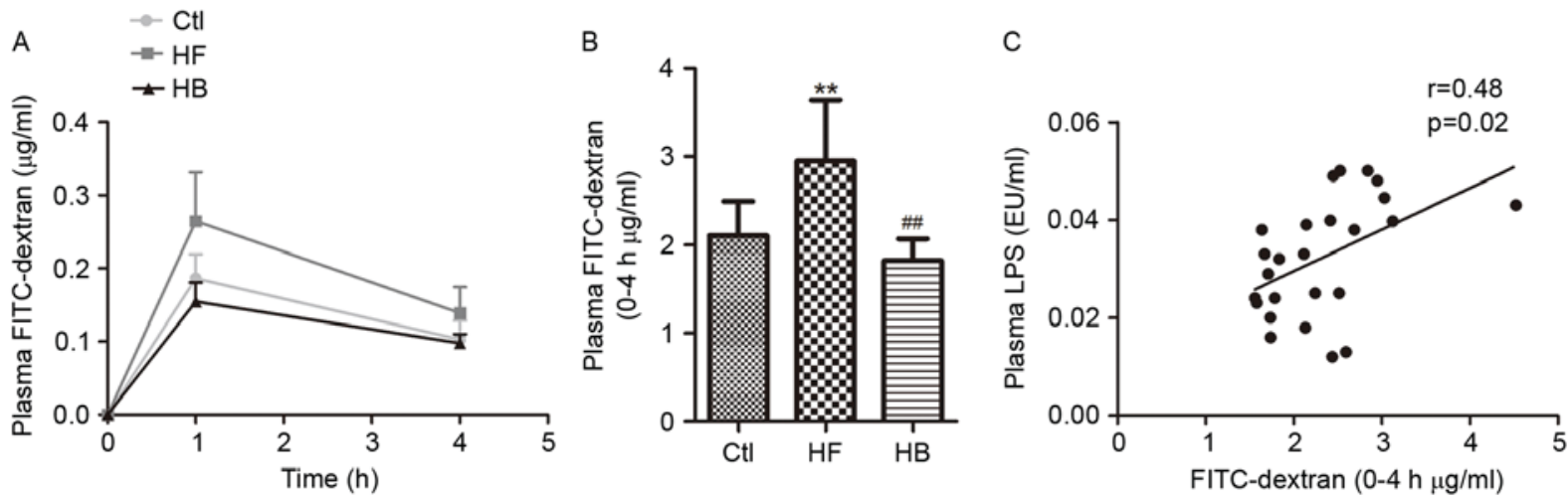

Figure 5. Berberine reduced intestinal permeability in HFD-fed rats. (A) Plasma FITC-dextran concentration. (B) Total plasma FITC-dextran concentration. (C) Correlation between portal plasma LPS levels and plasma FITC-dextran concentration. The inset corresponds to Pearson's correlation and the corresponding P-value. Data are expressed as the mean \pm standard deviation. ${ }^{* *} \mathrm{P}<0.01$ compared with the $\mathrm{Ctl}$ group; ${ }^{\# \#} \mathrm{P}<0.01$ compared with the HF group. Ctl, normal diet; HF, HFD; HB, HFD supplemented with berberine for 6 weeks; HFD, high-fat diet; FITC, fluorescein isothiocyanate; LPS, lipopolysaccharide; EU, endotoxin unit.

A

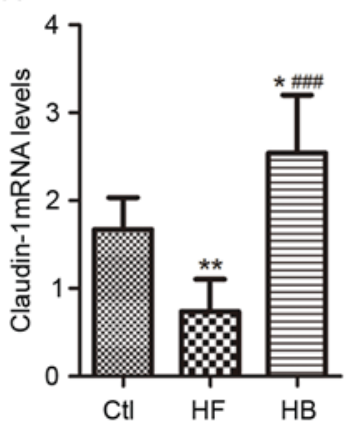

B

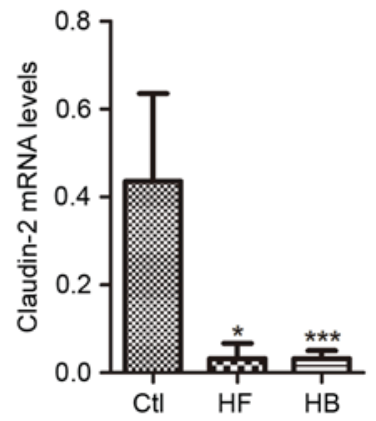

C

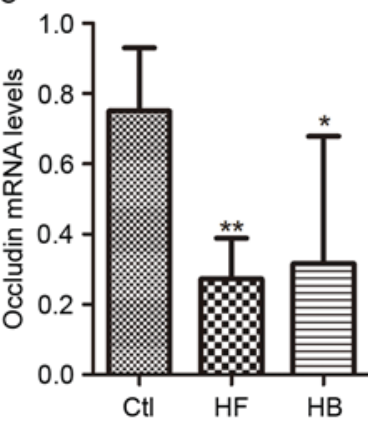

D

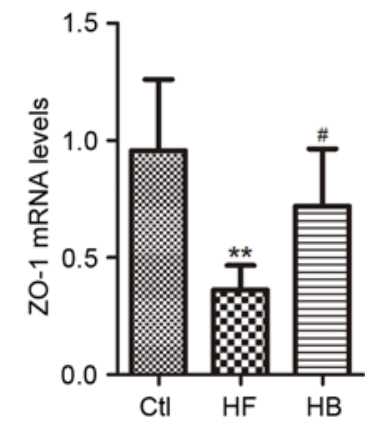

Figure 6. Berberine restored the expression of tight junction proteins in HFD-fed rats. mRNA expression levels of colonic epithelial tight junction proteins (A) claudin-1, (B) claudin-2, (C) occludin and (D) ZO-1. Data are expressed as the mean \pm standard deviation. ${ }^{*} \mathrm{P}<0.05,{ }^{* *} \mathrm{P}<0.01,{ }^{* * * *} \mathrm{P}<0.001$ compared with the Ctl group; ${ }^{\# P}<0.05,{ }^{\# \# "} \mathrm{P}<0.001$ compared with the HF group. Ctl, normal diet; HF, HFD; HB, HFD supplemented with berberine for 6 weeks; HFD, high-fat diet; ZO-1, zonula occludens-1.

in HFD-fed rats compared with in control rats (Fig. 3B-H). Treatment with berberine significantly reduced IL-1 $\beta$, PAI-1, STAMP-2, NADPHox, MCP-1 and F4/80 mRNA expression levels compared with in untreated HFD-fed rats (Fig. 3C-H). Berberine appeared to have no effect on TNF- $\alpha$ mRNA levels compared with in untreated HFD-fed rats (Fig. 3B).

To explore whether endotoxemia affected inflammatory processes in visceral adipose tissue, the correlation between LPS plasma levels and TNF- $\alpha$, IL-1 $\beta$, PAI-1, STAMP-2, NADPHox, MCP-1 and F4/80 mRNA expression levels was investigated. The present results indicated that LPS portal plasma levels were positively correlated with the mRNA expression levels of TNF $\alpha$, IL-1 $\beta$, PAI-1, NADPHox, STAMP2, MCP-1 and F4/80 in visceral adipose tissue (Fig. 4A-G). These multiple correlations suggested that gut microbiota and endotoxemia may synergistically contribute to inflammation, oxidative stress and macrophage infiltration in HFD-fed rats.

Berberine reduces intestinal permeability and ameliorates the expression and distribution of tight junction proteins in $H F D$-fed rats. To investigate whether endotoxemia could exert an effect on intestinal permeability, the plasma concentration of FITC-dextran was examined. In accordance with the changes in plasma LPS levels, a marked increase in plasma
FITC-dextran area under the curve was observed in HFD-fed rats compared with in the control rats (Fig. 5A). Treatment with berberine significantly reduced plasma FITC-dextran concentration in the HFD-fed rats compared with in untreated rats (Fig. 5A and B). Furthermore, portal plasma LPS levels appeared to be positively correlated with plasma FITC-dextran concentration (Fig. 5C). These findings suggested that berberine may reduce HFD-induced endotoxemia, through interfering with the control of intestinal permeability.

Tight junction proteins control paracellular permeability. In the present study, the effect of berberine on the expression and distribution of candidate tight junction proteins, including claudin-1, claudin-2, zonula occludens-1 (ZO-1) and occludin, was investigated using RT-qPCR and immunofluorescence. Claudin-1, claudin-2, ZO-1 and occludin mRNA expression levels in the proximal colon segments from HFD-fed rats were significantly decreased, as compared with rats in the control group. Treatment with berberine appeared to restore claudin-1 and ZO-1 mRNA expression levels, however, it had no significant effect on claudin-2 and occludin mRNA expression levels (Fig. 6A-D).

As shown in Fig. 7, immunofluorescence revealed that the tight junction proteins claudin-1 and claudin-2 are normally distributed along the epithelial sheet from the crypt to the 

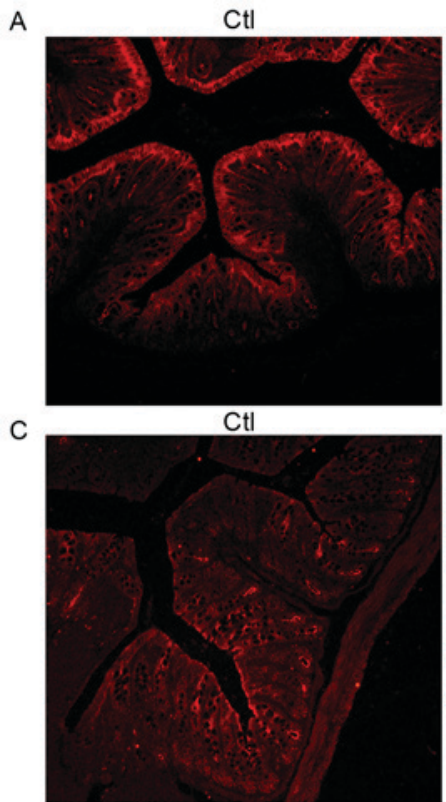

$\mathrm{HF}$

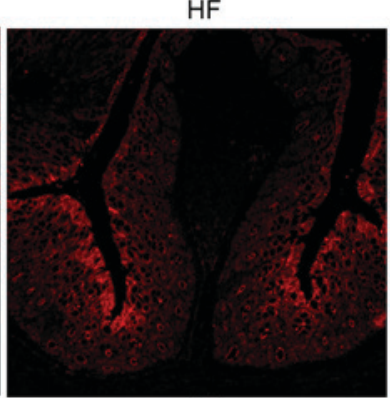

HF

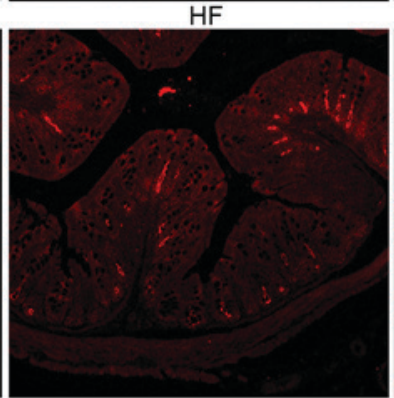

$\mathrm{HB}$
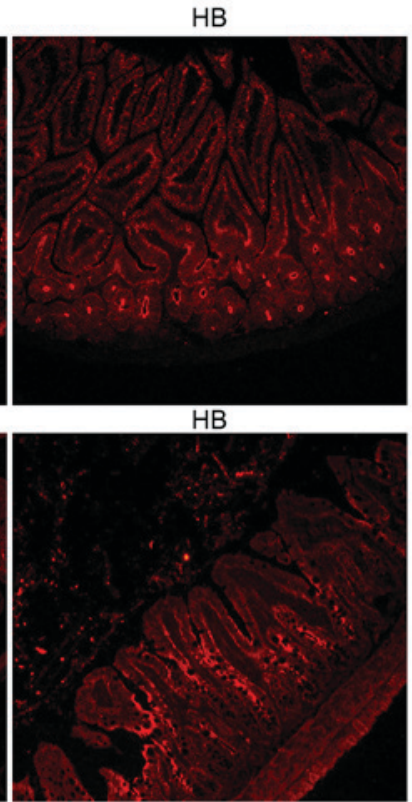

B
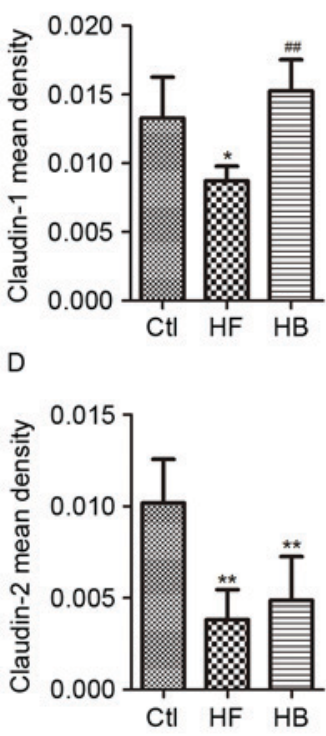

Figure 7. Berberine restored the expression and distribution of claudin-1 and claudin-2 in HFD-fed rats. (A) Immunofluorescent staining for claudin-1 (magnification, x100). (B) Immunohistochemistry score for claudin-1. (C) Immunofluorescent staining for claudin-2 (magnification, x100). (D) Immunohistochemistry score for claudin-2. Data are expressed as the mean \pm standard deviation. ${ }^{*} \mathrm{P}<0.05,{ }^{* * *} \mathrm{P}<0.01$ compared with the Ctl group; ${ }^{\# \#} \mathrm{P}<0.01$ compared with the HF group. Ctl, normal diet; HF, HFD; HB, HFD supplemented with berberine for 6 weeks; HFD, high-fat diet.
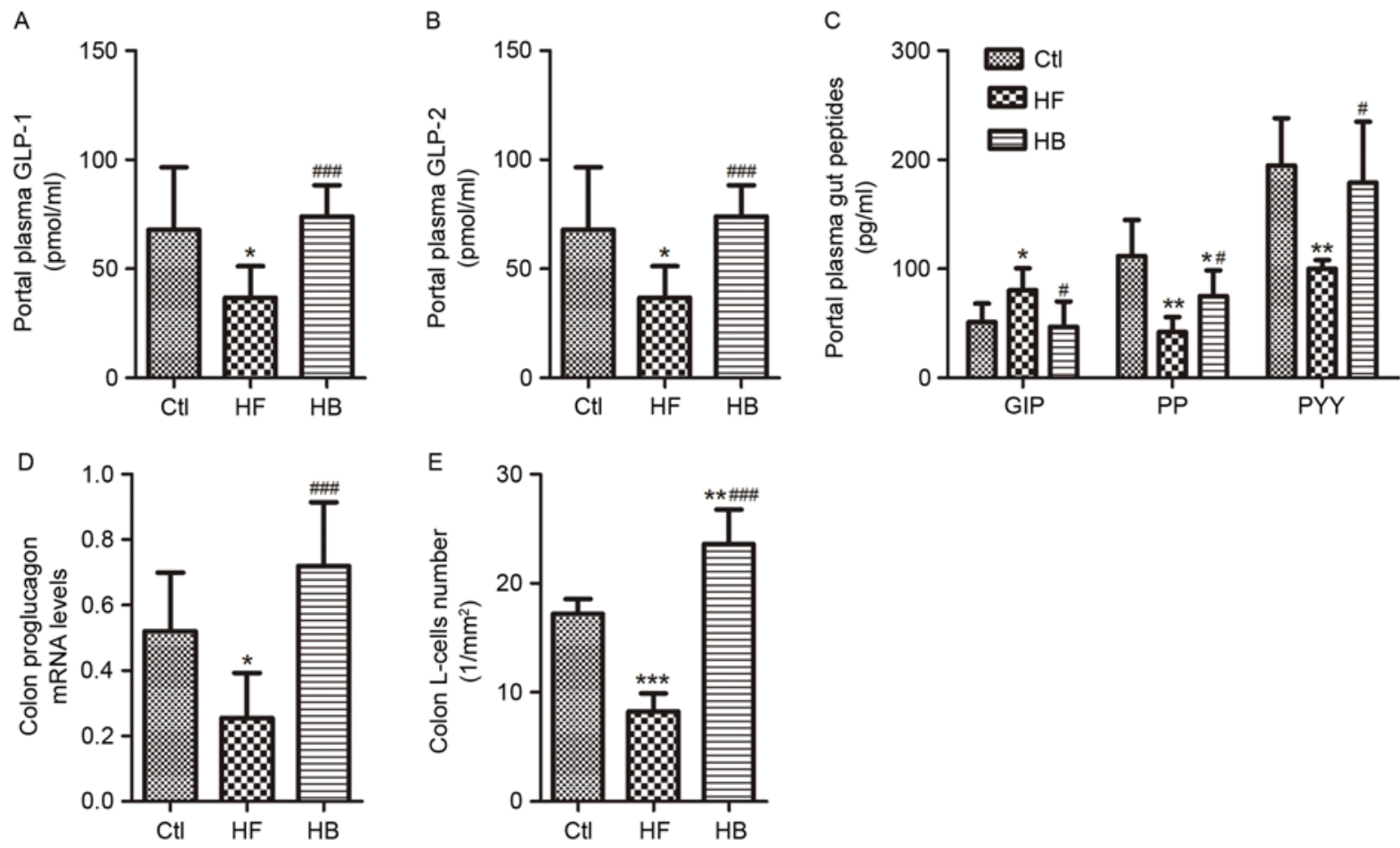

Figure 8. Berberine modulated intestinal hormone levels in portal plasma of HFD-fed rats. (A) Portal plasma GLP-1 levels. (B) Portal plasma GLP-2 levels. (C) Portal plasma GIP, PP and PYY levels. (D) Colonic proglucagon mRNA expression levels. (E) Colonic L-cell numbers. Data are expressed as the mean \pm standard deviation. ${ }^{*} \mathrm{P}<0.05,{ }^{* *} \mathrm{P}<0.01,{ }^{* * *} \mathrm{P}<0.001$ compared with the $\mathrm{Ctl}$ group; ${ }^{*} \mathrm{P}<0.05,{ }^{\# \# \#} \mathrm{P}<0.001$ compared with the HF group. Ctl, normal diet; HF, HFD; HB, HFD supplemented with berberine for 6 weeks; HFD, high-fat diet; GLP, glucagon-like peptide; GIP, gastric inhibitory polypeptide; PP, pancreatic polypeptide; PYY, peptide YY.

villous, and the staining for both proteins appeared continuous and dense. Conversely, in HFD-fed rats, the staining revealed a translocation of claudin-1 and claudin-2 from the tight junction to the luminal side of the crypt. Tissue from berberine-treated rats exhibited strong claudin- 1 and claudin-2 staining in the villous surface, similar to the control group (Fig. 7A and C). These observations suggested that berberine treatment may attenuate the HFD-induced redistribution of claudin- 1 and claudin-2. Furthermore, in accordance with the mRNA analysis results, the immunohistochemical staining scores (quantified 


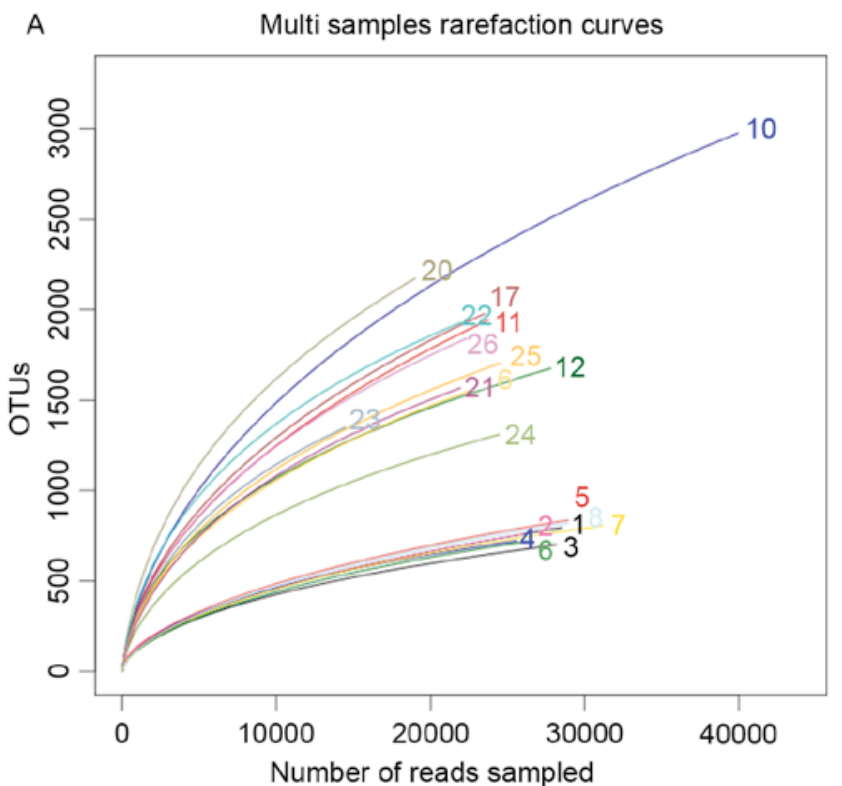

Label: 0.03

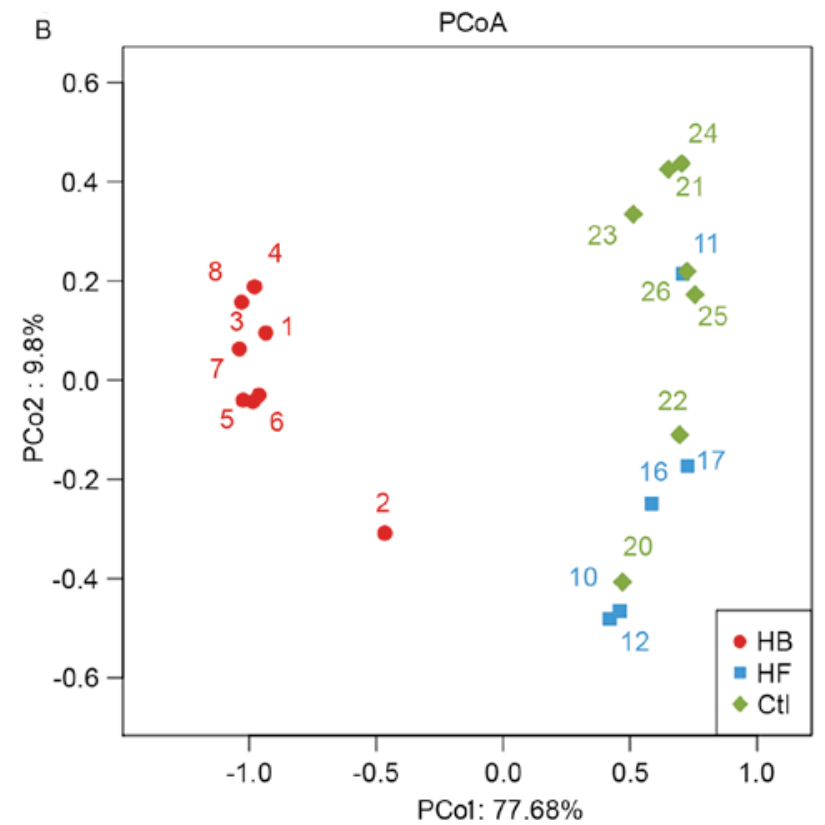

PCA
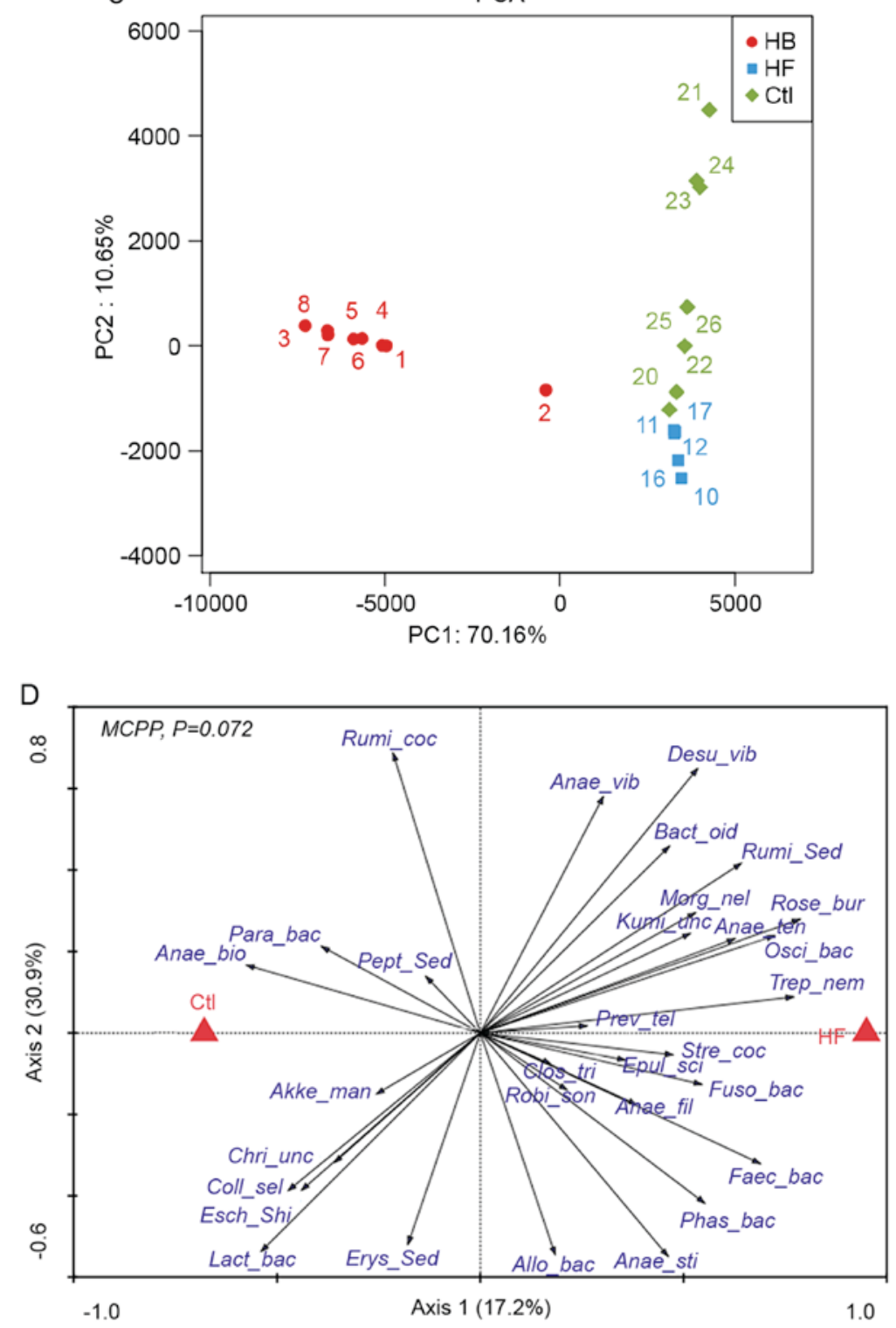

Figure 9. Berberine altered the gut microbiota composition in HFD-fed rats. (A) Rarefaction curves. (B) Weighted UniFrac PCoA. Each point represents the microbiota of each rat in the Ctl, HF and HB groups. (C) PCA. P-values were calculated by MCPP. (D) RDA between the Ctl and HF groups. 

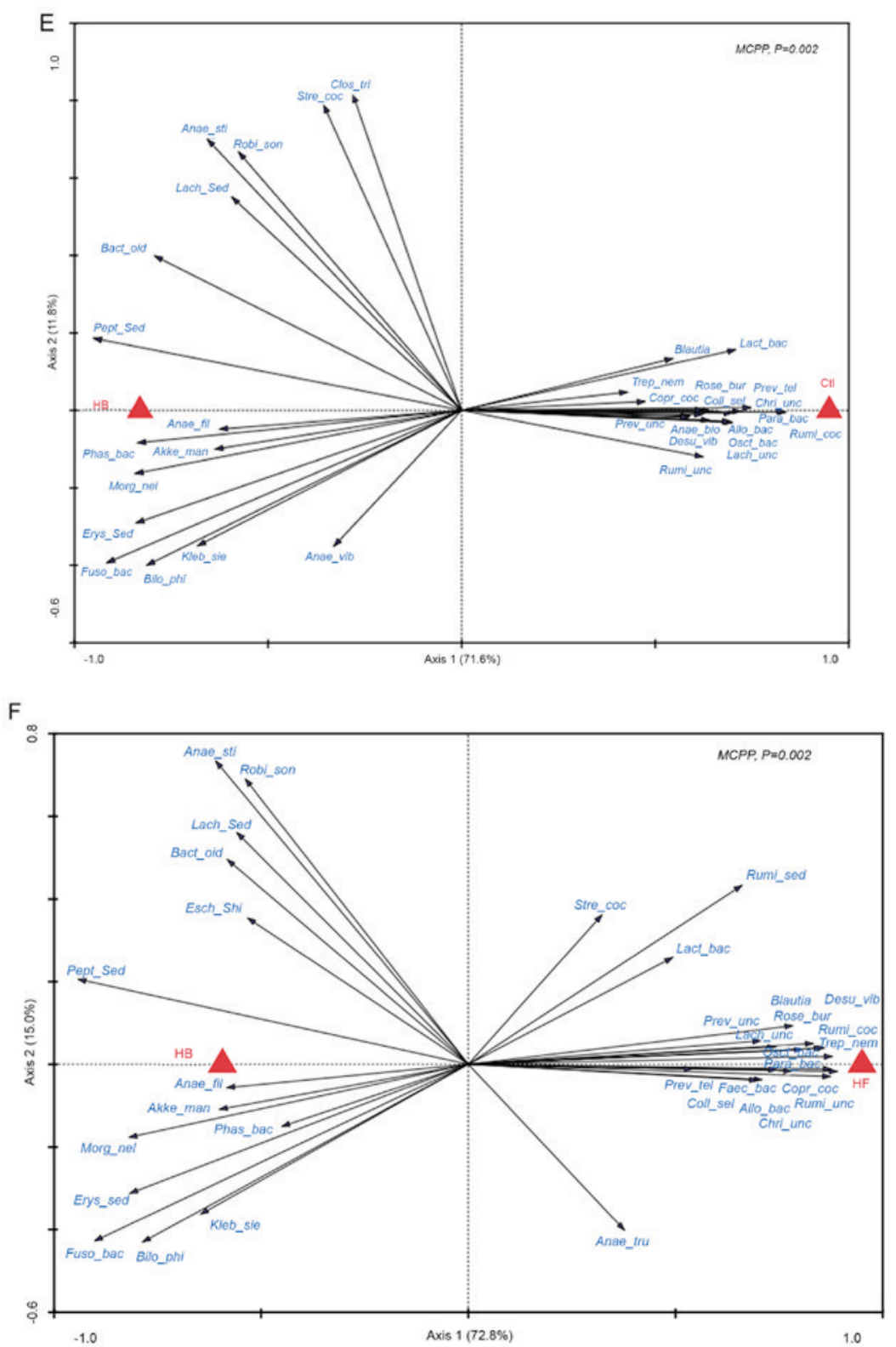

Figure 9. Continued. Berberine altered the gut microbiota composition in HFD-fed rats. (E) RDA between the Ctl and HB groups. (F) RDA between the HB and HF groups. P-values were calculated by MCPP. Ctl, normal diet; HF, HFD; HB, HFD supplemented with berberine for 6 weeks; HFD, high-fat diet; PCoA , principal coordinates analysis; PCA, principal components analysis; RDA, redundancy analysis; MCPP, Monte Carlo permutation tests.

by v.6 Image-Pro Plus software) for claudin-1 protein appeared significantly higher in berberine-treated rats compared with in untreated HFD-fed rats (Fig. 7B and D).

Berberine modulates intestinal hormone levels in portal plasma. Levels of the intestinal hormones GLP-1, GLP-2, PP and PYY appeared to be significantly reduced, whereas GIP levels were significantly increased in portal plasma samples of HFD-fed rats. Treatment with berberine restored the concentrations of GLP-1, GLP-2, PYY and GIP to those of the control rats (Fig. 8A-C). Furthermore, berberine almost doubled the portal plasma GLP-1 and GLP-2 levels as compared with HFD-fed rats. Berberine supplementation increased PP plasma levels significantly (Fig. 8C). In addition, berberine-treated rats exhibited a 3 -fold increase in proglucagon mRNA expression levels and in the number of GLP-1-positive L-cells in the proximal colon compared with HFD-fed untreated rats (Fig. 8D and E).

Berberine alters the composition of the gut microbiome. In order to investigate the effects of a HFD and berberine intake on the composition of the gut microbiome, 454 pyrosequencing of the bacterial 16S rRNA gene V1-V3 region was performed. A total of 602,852 usable reads $(119,071$ unique sequences) obtained from 20 samples were delineated into 10,385 operational taxonomic units (OTUs) at the $97 \%$ similarity level. Rarefaction curves indicated that most of the diversity of each microbial group was successfully sampled (Fig. 9A). Berberine supplementation appeared to cause a significant reduction in the richness of the gut microbiota, as compared with HFD-fed untreated rats, which was confirmed by Ace and Chao estimators (Table II). Berberine treatment 
Table II. Community richness and diversity estimator.

\begin{tabular}{llclllll}
\hline Sample ID $^{\mathrm{a}}$ & Reads $^{\mathrm{b}}$ & OTU numbers & Ace & Chao & Coverage & Shannon & Simpson \\
\hline HB group & & & & & & & \\
1 & 28,506 & 794 & 1,932 & 1,493 & 0.986038 & 3.45 & 0.0915 \\
2 & 26,026 & 759 & 2,039 & 1,394 & 0.985361 & 4.07 & 0.0376 \\
3 & 27,962 & 697 & 1,462 & 1,234 & 0.988556 & 3.12 & 0.1485 \\
4 & 25,582 & 721 & 1,385 & 1,145 & 0.987726 & 3.32 & 0.1273 \\
5 & 28,941 & 836 & 1,867 & 1,406 & 0.986179 & 3.5 & 0.1033 \\
6 & 26,300 & 719 & 1,560 & 1,153 & 0.987262 & 3.36 & 0.1037 \\
7 & 31,163 & 805 & 1,636 & 1,310 & 0.988223 & 3.4 & 0.1044 \\
8 & 28,936 & 819 & 1,795 & 1,354 & 0.986557 & 3.28 & 0.1215 \\
HF group & & & & & & \\
10 & 39,945 & 2976 & 6,450 & 5,108 & 0.965578 & 5.71 & 0.0151 \\
11 & 23,455 & 1931 & 4,621 & 3,464 & 0.959497 & 5.45 & 0.0173 \\
12 & 27,799 & 1676 & 3,183 & 2,641 & 0.975143 & 5.47 & 0.0153 \\
16 & 22,767 & 1558 & 3,283 & 2,577 & 0.969254 & 5.04 & 0.0389 \\
17 & 23,426 & 1976 & 4,493 & 3,385 & 0.959959 & 5.59 & 0.012 \\
Ctl group & & & & & & & \\
20 & 19,005 & 2174 & 4,293 & 3,686 & 0.949277 & 6.2 & 0.0056 \\
21 & 21,938 & 1567 & 3,157 & 2,568 & 0.968183 & 4.54 & 0.0821 \\
22 & 22,005 & 1930 & 3,442 & 2,941 & 0.964281 & 5.7 & 0.0145 \\
23 & 14,470 & 1349 & 2,441 & 2,039 & 0.960539 & 4.47 & 0.114 \\
24 & 24,471 & 1310 & 2,556 & 2,186 & 0.976585 & 4.61 & 0.0424 \\
25 & 24,497 & 1704 & 3,447 & 2,924 & 0.968813 & 5.16 & 0.0217 \\
26 & 22,357 & 1842 & 3,873 & 3,162 & 0.961936 & 5.28 & 0.0218 \\
\hline
\end{tabular}

${ }^{\text {aS Sample names. }}{ }^{\text {b}}$ Trimmed sequence numbers assigned to OTUs. OTU, operational taxonomic unit; HB, high fat diet supplemented with berberine for 6 weeks; HF, high fat diet; $\mathrm{Ctl}$, normal diet.

also appeared to significantly reduce the diversity of the gut microbiota, which was confirmed by the Shannon and Simpson indices (Table II).

A total of 10,119 OTUs (contributing to $98.8 \%$ of all sequencing reads) were assigned to 19 phyla by Mothur analysis. The most abundant phyla included Firmicutes (7,432 OTUs, $70.3 \%$ of all reads), Bacteroidetes (1,044 OTUs, $10.4 \%$ of all reads), Fusobacteria (457 OTUs, $8.2 \%$ of all reads), Proteobacteria (509 OTUs, $6.1 \%$ of all reads) and Actinobacteria (348 OTUs, $3.0 \%$ of all reads). As revealed by taxon-based analysis, there was a significant decrease in the abundance of the Actinobacteria phylum in the HFD-fed group compared with in the control group, whereas no significant differences were observed in the Firmicutes, Bacteroidetes, Fusobacteria and Proteobacteria phyla (Table III). Berberine markedly altered the gut microbiota composition at the phylum level, significantly increasing the abundance of Fusobacteria and Proteobacteria, and decreasing the abundance of Firmicutes and Actinobacteria (Table III). Berberine had no effect on the abundance of the Bacteroidetes phylum. In addition, berberine appeared to significantly affect the abundance of 59 genera (Table III). Among these, 12 genera displayed a 10-fold increase, and 37 genera displayed a 10-fold decrease in average frequency, compared with the HFD group rats. Furthermore, 37 genera were identified exclusively in berberine-treated rats, whereas 18 genera were identified exclusively in HFD-fed untreated animals.

Weighted UniFrac PCoA was performed to provide an overview of the gut microbiota composition. The gut microbiota composition changed significantly in response to HFD and berberine administration (Fig. 9B). PCo 1 (accounting for $77.68 \%$ of total variance) mainly reflected the effects of berberine on gut microbiota composition, as PCo 1 separated the $\mathrm{HB}$ group from the $\mathrm{HF}$ and $\mathrm{Ctl}$ groups. PCo 2 (accounting for $9.8 \%$ of total variance) mainly reflected the effect of different diets, as PCo 2 separated the Ctl group from the HB and HF groups. These results suggested that berberine can shift the composition of the gut microbiome of HFD-fed rats towards that of control rats. Similar results were obtained from the PCA (Fig. 9C).

Specific genera of gut bacteria responded to treatment with berberine. RDA was used to identify specific bacterial genera whose abundance was affected by HFD or berberine supplementation. Results indicated that a HFD caused a slight change in the composition of gut microbiota (Fig. 9D), whereas berberine treatment led to a significant change in the gut microbiota composition (Fig. 9E), which was proven by the Monte Carlo permutation tests (MCPP; $\mathrm{P}=0.002$ ). Following treatment with berberine, the composition of the 
Table III. Differentially abundant features analysis at the phylum or genus level.

\begin{tabular}{|c|c|c|c|c|c|c|}
\hline \multirow[b]{2}{*}{ Phylum/Genus } & \multirow{2}{*}{$\begin{array}{c}\mathrm{HB}(\%) \\
\text { mean } \pm \mathrm{SD}\end{array}$} & \multirow{2}{*}{$\begin{array}{c}\mathrm{HF}(\%) \\
\text { mean } \pm \mathrm{SD}\end{array}$} & \multirow{2}{*}{$\begin{array}{c}\mathrm{Ctl}(\%) \\
\text { mean } \pm \mathrm{SD}\end{array}$} & \multicolumn{3}{|c|}{ P-value } \\
\hline & & & & HB vs. HF & $\mathrm{HF}$ vs. $\mathrm{Ctl}$ & $\mathrm{HB}$ vs. $\mathrm{Ctl}$ \\
\hline \multicolumn{7}{|l|}{ Phylum } \\
\hline Acidobacteria & $0.00135 \pm 0.00066$ & $0.00293 \pm 0.0008$ & $0.00199 \pm 0.00095$ & 0.43870 & 0.71705 & 0.68879 \\
\hline Actinobacteria & $0.02004 \pm 0.00564$ & $1.94705 \pm 0.72971$ & $7.24482 \pm 2.45339$ & 0.01408 & 0.04507 & 0.00631 \\
\hline Bacteroidetes & $11.37515 \pm 2.19301$ & $14.64713 \pm 3.97861$ & $7.62278 \pm 1.86003$ & 0.51500 & 0.11850 & 0.18400 \\
\hline$T M 7$ & $0.00182 \pm 0.0012$ & $0.18116 \pm 0.09689$ & $1.89118 \pm 0.6578$ & 0.06685 & 0.01307 & 0.00685 \\
\hline Chloroflexi & $0.00043 \pm 0.00043$ & $0 \pm 0$ & $0.00058 \pm 0.00058$ & 1.00000 & 1.00000 & 1.00000 \\
\hline Cyanobacteria & $0.00095 \pm 0.00095$ & $0.08708 \pm 0.06498$ & $0.06448 \pm 0.02119$ & 0.20177 & 0.74114 & 0.00562 \\
\hline Deferribacteres & $0 \pm 0$ & $0.00314 \pm 0.00194$ & $0.00756 \pm 0.00683$ & 0.02102 & 0.57029 & 0.25377 \\
\hline $\begin{array}{l}\text { Deinococcus- } \\
\text { Thermus }\end{array}$ & $0.00137 \pm 0.00095$ & $0.00085 \pm 0.00085$ & $0.00065 \pm 0.00065$ & 1.00000 & 1.00000 & 1.00000 \\
\hline Elusimicrobia & $0 \pm 0$ & $0.00207 \pm 0.00089$ & $0.00232 \pm 0.00114$ & 0.05521 & 1.00000 & 0.06384 \\
\hline Firmicutes & $34.07855 \pm 3.97821$ & $79.44588 \pm 4.13566$ & $79.69249 \pm 2.76575$ & 0.00000 & 0.89414 & 0.00000 \\
\hline Fusobacteria & $40.28194 \pm 4.39043$ & $0.12066 \pm 0.05127$ & $0.0163 \pm 0.00883$ & 0.00000 & 0.05379 & 0.00000 \\
\hline Gemmatimonadetes & $0.00095 \pm 0.00095$ & $0 \pm 0$ & $0.00058 \pm 0.00058$ & 0.52842 & 1.00000 & 1.00000 \\
\hline Lentisphaerae & $0 \pm 0$ & $0.00968 \pm 0.00386$ & $0.00389 \pm 0.00251$ & 0.01669 & 0.22271 & 0.00408 \\
\hline Nitrospirae & $0 \pm 0$ & $0.00072 \pm 0.00072$ & $0 \pm 0$ & 0.38079 & 0.48016 & 1.00000 \\
\hline Planctomycetes & $0.00044 \pm 0.00044$ & $0.00157 \pm 0.00097$ & $0 \pm 0$ & 0.56199 & 0.23056 & 1.00000 \\
\hline Proteobacteria & $11.05874 \pm 1.14416$ & $2.45033 \pm 0.51587$ & $2.29854 \pm 0.57357$ & 0.00000 & 0.81821 & 0.00000 \\
\hline Spirochaetes & $0.0013 \pm 0.0013$ & $0.89612 \pm 0.16617$ & $0.20734 \pm 0.11901$ & 0.00015 & 0.00286 & 0.07762 \\
\hline Tenericutes & $0.013 \pm 0.01151$ & $0.12251 \pm 0.08587$ & $0.88127 \pm 0.36557$ & 0.22892 & 0.05143 & 0.02031 \\
\hline Verrucomicrobia & $3.14836 \pm 1.01832$ & $0.00072 \pm 0.00072$ & $0.00646 \pm 0.00424$ & 0.00469 & 0.19707 & 0.00492 \\
\hline \multicolumn{7}{|l|}{ Genus } \\
\hline Acetanaerobacterium & $0.00595 \pm 0.00473$ & $0 \pm 0$ & $0 \pm 0$ & 0.22569 & 1.00000 & 0.22139 \\
\hline $\begin{array}{l}\text { Acetobacteraceae_- } \\
\text { uncultured }\end{array}$ & $0 \pm 0$ & $0 \pm 0$ & $0.00065 \pm 0.00065$ & 1.00000 & 1.00000 & 0.39968 \\
\hline Acholeplasma & $0 \pm 0$ & $0 \pm 0$ & $0.00117 \pm 0.00117$ & 1.00000 & 0.50079 & 0.15974 \\
\hline $\begin{array}{l}\text { Acidobacteriaceae_ } \\
\text { uncultured }\end{array}$ & $0 \pm 0$ & $0 \pm 0$ & $0.00075 \pm 0.00075$ & 1.00000 & 1.00000 & 0.39968 \\
\hline Acidothermus & $0 \pm 0$ & $0.00072 \pm 0.00072$ & $0 \pm 0$ & 0.38079 & 0.48016 & 1.00000 \\
\hline Acidovorax & $0.00048 \pm 0.00048$ & $0 \pm 0$ & $0.00058 \pm 0.00058$ & 1.00000 & 1.00000 & 1.00000 \\
\hline Acinetobacter & $0.00179 \pm 0.00133$ & $0 \pm 0$ & $0 \pm 0$ & 0.30479 & 1.00000 & 0.15540 \\
\hline Actinomyces & $0.00315 \pm 0.00127$ & $0.01949 \pm 0.01252$ & $0.00564 \pm 0.00313$ & 0.21147 & 0.30068 & 0.55334 \\
\hline Adlercreutzia & $0 \pm 0$ & $0.00562 \pm 0.00501$ & $0.03181 \pm 0.00825$ & 0.29136 & 0.01312 & 0.00060 \\
\hline Aeribacillus & $0.00086 \pm 0.00086$ & $0.00088 \pm 0.00088$ & $0 \pm 0$ & 1.00000 & 0.48016 & 0.52013 \\
\hline $\begin{array}{l}\text { Aerococcaceae_ } \\
\text { uncultured }\end{array}$ & $0.00044 \pm 0.00044$ & $0 \pm 0$ & $0 \pm 0$ & 1.00000 & 1.00000 & 1.00000 \\
\hline Aerococcus & $0 \pm 0$ & $0.00088 \pm 0.00088$ & $0 \pm 0$ & 0.38079 & 0.48016 & 1.00000 \\
\hline Agrococcus & $0.00043 \pm 0.00043$ & $0 \pm 0$ & $0 \pm 0$ & 1.00000 & 1.00000 & 1.00000 \\
\hline Akkermansia & $3.14836 \pm 1.01832$ & $0 \pm 0$ & $0.00447 \pm 0.00447$ & 0.00472 & 0.34499 & 0.00353 \\
\hline Alcaligenes & $0 \pm 0$ & $0.00288 \pm 0.00288$ & $0 \pm 0$ & 0.02102 & 0.05316 & 1.00000 \\
\hline Alistipes & $0 \pm 0$ & $0.00423 \pm 0.00266$ & $0.02031 \pm 0.00915$ & 0.12302 & 0.10822 & 0.03099 \\
\hline Allobaculum & $0.00311 \pm 0.00079$ & $10.84206 \pm 3.94134$ & $8.82073 \pm 2.9406$ & 0.01252 & 0.74820 & 0.00424 \\
\hline Anaerobiospirillum & $0.00049 \pm 0.00049$ & $0.00088 \pm 0.00088$ & $0.46779 \pm 0.17407$ & 1.00000 & 0.01388 & 0.00936 \\
\hline Anaerofilum & $2.30376 \pm 0.73263$ & $0.05499 \pm 0.02737$ & $0.0219 \pm 0.01234$ & 0.00482 & 0.28611 & 0.00332 \\
\hline Anaerofustis & $0 \pm 0$ & $0.01313 \pm 0.01103$ & $0.0104 \pm 0.00328$ & 0.26065 & 0.84805 & 0.00274 \\
\hline $\begin{array}{l}\text { Anaerolineaceae_ } \\
\text { uncultured }\end{array}$ & $0 \pm 0$ & $0 \pm 0$ & $0.00058 \pm 0.00058$ & 1.00000 & 1.00000 & 0.39968 \\
\hline Anaerostipes & $1.29186 \pm 0.40432$ & $0.04986 \pm 0.02226$ & $0.01231 \pm 0.01159$ & 0.00484 & 0.14894 & 0.00282 \\
\hline Anaerotruncus & $0.77713 \pm 0.36482$ & $1.53538 \pm 0.27758$ & $0.81297 \pm 0.35685$ & 0.10951 & 0.12560 & 0.94840 \\
\hline Anaerovibrio & $1.03718 \pm 0.22773$ & $1.00465 \pm 0.37017$ & $0.78444 \pm 0.45957$ & 0.93799 & 0.77328 & 0.70861 \\
\hline
\end{tabular}


Table III. Continued.

\begin{tabular}{|c|c|c|c|c|c|c|}
\hline \multirow[b]{2}{*}{ Phylum/Genus } & \multirow{2}{*}{$\begin{array}{c}\mathrm{HB}(\%) \\
\text { mean } \pm \mathrm{SD}\end{array}$} & \multirow{2}{*}{$\begin{array}{c}\mathrm{HF}(\%) \\
\text { mean } \pm \mathrm{SD}\end{array}$} & \multirow{2}{*}{$\begin{array}{c}\mathrm{Ctl}(\%) \\
\text { mean } \pm \mathrm{SD}\end{array}$} & \multicolumn{3}{|c|}{$\mathrm{P}$-value } \\
\hline & & & & HB vs. HF & HF vs. Ctl & $\mathrm{HB}$ vs. $\mathrm{Ctl}$ \\
\hline Anaerovorax & $0 \pm 0$ & $0.01789 \pm 0.00528$ & $0.02409 \pm 0.00572$ & 0.00299 & 0.51230 & 0.00026 \\
\hline Anoxybacillus & $0.00183 \pm 0.00095$ & $0.00072 \pm 0.00072$ & $0.00239 \pm 0.00176$ & 0.65574 & 0.37696 & 0.72123 \\
\hline Aquabacterium & $0.00044 \pm 0.00044$ & $0 \pm 0$ & $0.0013 \pm 0.0013$ & 1.00000 & 0.50079 & 0.56788 \\
\hline Arenimonas & $0 \pm 0$ & $0 \pm 0$ & $0.00065 \pm 0.00065$ & 1.00000 & 1.00000 & 0.39968 \\
\hline Bacillus & $0.00438 \pm 0.00295$ & $0 \pm 0$ & $0.00129 \pm 0.00083$ & 0.14862 & 0.50079 & 0.33974 \\
\hline Bacteroides & $11.32657 \pm 2.19329$ & $2.86663 \pm 1.50674$ & $0.50319 \pm 0.25937$ & 0.00396 & 0.13701 & 0.00010 \\
\hline Barnesiella & $0 \pm 0$ & $0 \pm 0$ & $0.00064 \pm 0.00064$ & 1.00000 & 1.00000 & 0.39968 \\
\hline Bifidobacterium & $0 \pm 0$ & $0.00085 \pm 0.00085$ & $0 \pm 0$ & 0.38079 & 0.48016 & 1.00000 \\
\hline Bilophila & $0.79589 \pm 0.15162$ & $0.00085 \pm 0.00085$ & $0.00157 \pm 0.00106$ & 0.00046 & 1.00000 & 0.00003 \\
\hline Blautia & $0.80417 \pm 0.24782$ & $6.23756 \pm 1.76412$ & $6.90259 \pm 2.62767$ & 0.00509 & 0.86245 & 0.02394 \\
\hline Brachybacterium & $0 \pm 0$ & $0 \pm 0$ & $0.00197 \pm 0.00197$ & 1.00000 & 0.50079 & 0.15974 \\
\hline Bradyrhizobium & $0 \pm 0$ & $0 \pm 0$ & $0.00065 \pm 0.00065$ & 1.00000 & 1.00000 & 0.39968 \\
\hline Brevundimonas & $0.00216 \pm 0.00113$ & $0 \pm 0$ & $0 \pm 0$ & 0.16413 & 1.00000 & 0.16476 \\
\hline Burkholderia & $0.01374 \pm 0.00306$ & $0.00895 \pm 0.00321$ & $0.00898 \pm 0.00396$ & 0.31982 & 0.98550 & 0.42879 \\
\hline Butyricicoccus & $0 \pm 0$ & $0 \pm 0$ & $0.00058 \pm 0.00058$ & 1.00000 & 1.00000 & 0.39968 \\
\hline Butyricimonas & $0 \pm 0$ & $0.00602 \pm 0.00423$ & $0.00075 \pm 0.00075$ & 0.16249 & 0.23333 & 0.39968 \\
\hline $\begin{array}{l}\text { Candidatus_- } \\
\text { Arthromitus }\end{array}$ & $0 \pm 0$ & $0.0005 \pm 0.0005$ & $0.00559 \pm 0.00411$ & 0.38079 & 0.23120 & 0.18080 \\
\hline $\begin{array}{l}\text { Candidatus_ }_{-} \\
\text {Chloracidobacterium }\end{array}$ & $0.00091 \pm 0.00059$ & $0.00135 \pm 0.00087$ & $0 \pm 0$ & 0.63837 & 0.23056 & 0.52013 \\
\hline $\begin{array}{l}\text { Candidatus_ } \\
\text { Solibacter }\end{array}$ & $0 \pm 0$ & $0 \pm 0$ & $0.00065 \pm 0.00065$ & 1.00000 & 1.00000 & 0.39968 \\
\hline Caulobacter & $0.00044 \pm 0.00044$ & $0 \pm 0$ & $0 \pm 0$ & 1.00000 & 1.00000 & 1.00000 \\
\hline Cellulosilyticum & $0.00048 \pm 0.00048$ & $0 \pm 0$ & $0 \pm 0$ & 1.00000 & 1.00000 & 1.00000 \\
\hline $\begin{array}{l}\text { Christensenellaceae_ } \\
\text { uncultured }\end{array}$ & $0 \pm 0$ & $0.50197 \pm 0.122$ & $1.05035 \pm 0.29907$ & 0.00139 & 0.10517 & 0.00119 \\
\hline Christensenella & $0 \pm 0$ & $0.00765 \pm 0.00241$ & $0.07967 \pm 0.01597$ & 0.00398 & 0.00051 & 0.00007 \\
\hline Chryseobacterium & $0.00136 \pm 0.00066$ & $0 \pm 0$ & $0 \pm 0$ & 0.29263 & 1.00000 & 0.28019 \\
\hline Clostridium & $1.0162 \pm 0.90173$ & $0.00465 \pm 0.00191$ & $0.0035 \pm 0.00288$ & 0.29069 & 0.79322 & 0.27462 \\
\hline Collinsella & $0 \pm 0$ & $1.75193 \pm 0.70971$ & $6.94762 \pm 2.43052$ & 0.02134 & 0.05349 & 0.00609 \\
\hline Comamonas & $0.00588 \pm 0.00213$ & $0.00229 \pm 0.00148$ & $0.00369 \pm 0.00194$ & 0.18018 & 0.51090 & 0.54084 \\
\hline Coprococcus & $0.00187 \pm 0.00101$ & $0.34846 \pm 0.07673$ & $0.44409 \pm 0.23277$ & 0.00092 & 0.76015 & 0.06288 \\
\hline $\begin{array}{l}\text { Coriobacteriaceae_ } \\
\text { uncultured }\end{array}$ & $0.00044 \pm 0.00044$ & $0.07323 \pm 0.01542$ & $0.07895 \pm 0.02065$ & 0.00080 & 0.85713 & 0.00067 \\
\hline Corynebacterium & $0 \pm 0$ & $0.00751 \pm 0.00291$ & $0.00305 \pm 0.00119$ & 0.01717 & 0.17098 & 0.01020 \\
\hline Deinococcus & $0.00137 \pm 0.00095$ & $0.00085 \pm 0.00085$ & $0.00065 \pm 0.00065$ & 1.00000 & 1.00000 & 1.00000 \\
\hline Delftia & $0.02537 \pm 0.00587$ & $0.00866 \pm 0.00411$ & $0.01068 \pm 0.00254$ & 0.02783 & 0.74368 & 0.02491 \\
\hline Desemzia & $0.00048 \pm 0.00048$ & $0 \pm 0$ & $0 \pm 0$ & 1.00000 & 1.00000 & 1.00000 \\
\hline Desulfovibrio & $0.13322 \pm 0.0136$ & $2.12679 \pm 0.44718$ & $1.30345 \pm 0.47798$ & 0.00099 & 0.22106 & 0.01686 \\
\hline Devosia & $0.00092 \pm 0.0006$ & $0 \pm 0$ & $0 \pm 0$ & 0.52842 & 1.00000 & 0.52013 \\
\hline Diaphorobacter & $0.00049 \pm 0.00049$ & $0 \pm 0$ & $0.00117 \pm 0.00117$ & 1.00000 & 0.50079 & 0.56788 \\
\hline Elusimicrobium & $0 \pm 0$ & $0.00207 \pm 0.00089$ & $0.00232 \pm 0.00114$ & 0.05521 & 1.00000 & 0.06384 \\
\hline Enhydrobacter & $0.00084 \pm 0.00055$ & $0 \pm 0$ & $0 \pm 0$ & 0.52842 & 1.00000 & 0.52013 \\
\hline Enterococcus & $0.3229 \pm 0.06599$ & $0.002 \pm 0.002$ & $0.00649 \pm 0.00376$ & 0.00075 & 0.31480 & 0.00011 \\
\hline Enterorhabdus & $0.00043 \pm 0.00043$ & $0.01485 \pm 0.00579$ & $0.07087 \pm 0.0206$ & 0.02093 & 0.01589 & 0.00164 \\
\hline Epulopiscium & $0.1753 \pm 0.17421$ & $0.00088 \pm 0.00088$ & $0 \pm 0$ & 0.36952 & 0.48016 & 0.34371 \\
\hline Erysipelothrix & $0.00096 \pm 0.00096$ & $0 \pm 0$ & $0 \pm 0$ & 0.52842 & 1.00000 & 0.52013 \\
\hline $\begin{array}{l}\text { Erysipelotrichaceae_ } \\
\text { Incertae_Sedis }\end{array}$ & $2.50531 \pm 0.39665$ & $0.00672 \pm 0.00292$ & $0.01301 \pm 0.00902$ & 0.00017 & 0.58704 & 0.00002 \\
\hline
\end{tabular}


Table III. Continued.

\begin{tabular}{|c|c|c|c|c|c|c|}
\hline \multirow[b]{2}{*}{ Phylum/Genus } & \multirow{2}{*}{$\begin{array}{c}\mathrm{HB}(\%) \\
\text { mean } \pm \mathrm{SD}\end{array}$} & \multirow{2}{*}{$\begin{array}{c}\mathrm{HF}(\%) \\
\text { mean } \pm \mathrm{SD}\end{array}$} & \multirow{2}{*}{$\begin{array}{c}\mathrm{Ctl}(\%) \\
\text { mean } \pm \mathrm{SD}\end{array}$} & \multicolumn{3}{|c|}{ P-value } \\
\hline & & & & HB vs. HF & $\mathrm{HF}$ vs. Ctl & $\mathrm{HB}$ vs. $\mathrm{Ctl}$ \\
\hline $\begin{array}{l}\text { Erysipelotrichaceae_ } \\
\text { uncultured }\end{array}$ & $0 \pm 0$ & $0.00648 \pm 0.00587$ & $0.01533 \pm 0.00785$ & 0.30366 & 0.45472 & 0.05456 \\
\hline Escherichia-Shigella & $0.35447 \pm 0.11707$ & $0.02743 \pm 0.00973$ & $0.32604 \pm 0.1537$ & 0.01092 & 0.07005 & 0.90572 \\
\hline Faecalibacterium & $0.00173 \pm 0.00131$ & $0.81438 \pm 0.32885$ & $0.00058 \pm 0.00058$ & 0.02116 & 0.02256 & 0.65440 \\
\hline $\begin{array}{l}\text { Family_XIII_ } \\
\text { Incertae_Sedis_ } \\
\text { Incertae_Sedis }\end{array}$ & $0 \pm 0$ & $0.10057 \pm 0.02552$ & $0.20788 \pm 0.04714$ & 0.00163 & 0.06129 & 0.00018 \\
\hline $\begin{array}{l}\text { Family_XIII_ } \\
\text { Incertae_Sedis_ } \\
\text { uncultured }\end{array}$ & $0 \pm 0$ & $0.36272 \pm 0.09627$ & $0.21403 \pm 0.05279$ & 0.00193 & 0.19001 & 0.00036 \\
\hline Ferruginibacter & $0.0008 \pm 0.0008$ & $0 \pm 0$ & $0.00058 \pm 0.00058$ & 0.52842 & 1.00000 & 1.00000 \\
\hline Flavobacterium & $0.00096 \pm 0.00096$ & $0.00264 \pm 0.00264$ & $0.00058 \pm 0.00058$ & 0.37584 & 0.35637 & 1.00000 \\
\hline Flavonifractor & $0.01386 \pm 0.01386$ & $0.00451 \pm 0.00451$ & $0.0693 \pm 0.05199$ & 0.61083 & 0.22530 & 0.32534 \\
\hline Flexibacter & $0.00048 \pm 0.00048$ & $0 \pm 0$ & $0.0013 \pm 0.0013$ & 1.00000 & 0.50079 & 0.56788 \\
\hline Fusobacterium & $40.17087 \pm 4.4684$ & $0.03271 \pm 0.01065$ & $0.01066 \pm 0.00678$ & 0.00004 & 0.09584 & 0.00000 \\
\hline $\begin{array}{l}\text { GKS98_freshwater_ } \\
\text { group }\end{array}$ & $0.00088 \pm 0.00088$ & $0 \pm 0$ & $0 \pm 0$ & 0.52842 & 1.00000 & 0.52013 \\
\hline Gelria & $0 \pm 0$ & $0.0005 \pm 0.0005$ & $0 \pm 0$ & 0.38079 & 0.48016 & 1.00000 \\
\hline Gemella & $0.00776 \pm 0.00299$ & $0.16081 \pm 0.06141$ & $0.00508 \pm 0.00187$ & 0.02078 & 0.01988 & 0.53684 \\
\hline $\begin{array}{l}\text { Gemmatimonadac } \\
\text { eae_uncultured }\end{array}$ & $0.00095 \pm 0.00095$ & $0 \pm 0$ & $0 \pm 0$ & 0.52842 & 1.00000 & 0.52013 \\
\hline Geobacillus & $0.00087 \pm 0.00057$ & $0 \pm 0$ & $0 \pm 0$ & 0.52842 & 1.00000 & 0.52013 \\
\hline Globicatella & $0 \pm 0$ & $0 \pm 0$ & $0.00129 \pm 0.00083$ & 1.00000 & 0.50079 & 0.15974 \\
\hline Granulicatella & $0 \pm 0$ & $0.00088 \pm 0.00088$ & $0 \pm 0$ & 0.38079 & 0.48016 & 1.00000 \\
\hline Haliangium & $0.00048 \pm 0.00048$ & $0 \pm 0$ & $0 \pm 0$ & 1.00000 & 1.00000 & 1.00000 \\
\hline Helicobacter & $0.07094 \pm 0.02612$ & $0.03422 \pm 0.01028$ & $0.01257 \pm 0.006$ & 0.20991 & 0.08585 & 0.03429 \\
\hline Herbaspirillum & $0 \pm 0$ & $0.00144 \pm 0.00144$ & $0 \pm 0$ & 0.14500 & 0.23056 & 1.00000 \\
\hline Holdemania & $0 \pm 0$ & $0.06632 \pm 0.01785$ & $0.09885 \pm 0.0582$ & 0.00208 & 0.66766 & 0.09437 \\
\hline $\begin{array}{l}\text { Hydrogenoanaero } \\
\text { bacterium }\end{array}$ & $0 \pm 0$ & $0.0005 \pm 0.0005$ & $0 \pm 0$ & 0.38079 & 0.48016 & 1.00000 \\
\hline Hydrogenophaga & $0 \pm 0$ & $0.00072 \pm 0.00072$ & $0.00065 \pm 0.00065$ & 0.38079 & 1.00000 & 0.39968 \\
\hline Iamia & $0.00048 \pm 0.00048$ & $0 \pm 0$ & $0 \pm 0$ & 1.00000 & 1.00000 & 1.00000 \\
\hline Janthinobacterium & $0.0004 \pm 0.0004$ & $0 \pm 0$ & $0 \pm 0$ & 1.00000 & 1.00000 & 1.00000 \\
\hline Jeotgalicoccus & $0.00044 \pm 0.00044$ & $0 \pm 0$ & $0 \pm 0$ & 1.00000 & 1.00000 & 1.00000 \\
\hline Klebsiella & $2.78132 \pm 0.76059$ & $0.0005 \pm 0.0005$ & $0.00122 \pm 0.00079$ & 0.00220 & 1.00000 & 0.00088 \\
\hline Kocuria & $0.00654 \pm 0.00483$ & $0 \pm 0$ & $0 \pm 0$ & 0.19016 & 1.00000 & 0.18444 \\
\hline $\begin{array}{l}\text { Lachnospiraceae_ } \\
\text { Incertae_Sedis }\end{array}$ & $3.56313 \pm 0.69197$ & $1.58603 \pm 0.57302$ & $1.85636 \pm 0.36867$ & 0.03981 & 0.75605 & 0.03432 \\
\hline $\begin{array}{l}\text { Lachnospiraceae_ } \\
\text { uncultured }\end{array}$ & $0.01129 \pm 0.00569$ & $6.64096 \pm 2.13871$ & $10.66917 \pm 3.4409$ & 0.00469 & 0.39685 & 0.00338 \\
\hline Lachnospira & $0 \pm 0$ & $0.00171 \pm 0.00171$ & $0.0047 \pm 0.00389$ & 0.14500 & 0.45570 & 0.01020 \\
\hline Lactobacillus & $0.69316 \pm 0.42232$ & $3.77028 \pm 2.08403$ & $16.53313 \pm 5.33947$ & 0.15694 & 0.03801 & 0.00458 \\
\hline Lactococcus & $0.0058 \pm 0.00206$ & $0.00072 \pm 0.00072$ & $0 \pm 0$ & 0.02900 & 0.48016 & 0.00690 \\
\hline Leifsonia & $0 \pm 0$ & $0 \pm 0$ & $0.00065 \pm 0.00065$ & 1.00000 & 1.00000 & 0.39968 \\
\hline Leptolyngbya & $0 \pm 0$ & $0 \pm 0$ & $0.00254 \pm 0.00194$ & 1.00000 & 0.12618 & 0.02552 \\
\hline Leptothrix & $0.00043 \pm 0.00043$ & $0 \pm 0$ & $0 \pm 0$ & 1.00000 & 1.00000 & 1.00000 \\
\hline Leucobacter & $0.00044 \pm 0.00044$ & $0.00088 \pm 0.00088$ & $0 \pm 0$ & 1.00000 & 0.48016 & 1.00000 \\
\hline Leuconostoc & $0.00314 \pm 0.00103$ & $0 \pm 0$ & $0 \pm 0$ & 0.04928 & 1.00000 & 0.04686 \\
\hline Luteimonas & $0 \pm 0$ & $0 \pm 0$ & $0.00099 \pm 0.00099$ & 1.00000 & 1.00000 & 0.39968 \\
\hline Lysobacter & $0 \pm 0$ & $0 \pm 0$ & $0.00058 \pm 0.00058$ & 1.00000 & 1.00000 & 0.39968 \\
\hline
\end{tabular}


Table III. Continued.

\begin{tabular}{|c|c|c|c|c|c|c|}
\hline \multirow[b]{2}{*}{ Phylum/Genus } & \multirow{2}{*}{$\begin{array}{c}\mathrm{HB}(\%) \\
\text { mean } \pm \mathrm{SD}\end{array}$} & \multirow{2}{*}{$\begin{array}{c}\mathrm{HF}(\%) \\
\text { mean } \pm \mathrm{SD}\end{array}$} & \multirow{2}{*}{$\begin{array}{c}\mathrm{Ctl}(\%) \\
\text { mean } \pm \mathrm{SD}\end{array}$} & \multicolumn{3}{|c|}{ P-value } \\
\hline & & & & HB vs. HF & HF vs. Ctl & $\mathrm{HB}$ vs. $\mathrm{Ctl}$ \\
\hline Marmoricola & $0.00048 \pm 0.00048$ & $0 \pm 0$ & $0 \pm 0$ & 1.00000 & 1.00000 & 1.00000 \\
\hline Marvinbryantia & $0 \pm 0$ & $0.15705 \pm 0.04201$ & $0.13174 \pm 0.03237$ & 0.00203 & 0.70828 & 0.00033 \\
\hline Megamonas & $0 \pm 0$ & $0 \pm 0$ & $0.00058 \pm 0.00058$ & 1.00000 & 1.00000 & 0.39968 \\
\hline Methylobacillus & $0 \pm 0$ & $0 \pm 0$ & $0.00065 \pm 0.00065$ & 1.00000 & 1.00000 & 0.39968 \\
\hline Methylobacterium & $0.00084 \pm 0.00055$ & $0 \pm 0$ & $0.00117 \pm 0.00117$ & 0.52842 & 0.50079 & 0.65412 \\
\hline Microbacterium & $0 \pm 0$ & $0.00176 \pm 0.00176$ & $0 \pm 0$ & 0.14500 & 0.23056 & 1.00000 \\
\hline Micrococcus & $0.0004 \pm 0.0004$ & $0 \pm 0$ & $0 \pm 0$ & 1.00000 & 1.00000 & 1.00000 \\
\hline Mogibacterium & $0 \pm 0$ & $0.10606 \pm 0.02317$ & $0.06192 \pm 0.03252$ & 0.00090 & 0.28500 & 0.06173 \\
\hline Morganella & $0.63669 \pm 0.10501$ & $0.00122 \pm 0.00077$ & $0 \pm 0$ & 0.00024 & 0.23056 & 0.00002 \\
\hline Mucilaginibacter & $0 \pm 0$ & $0 \pm 0$ & $0.0013 \pm 0.0013$ & 1.00000 & 0.50079 & 0.15974 \\
\hline Mucispirillum & $0 \pm 0$ & $0.00314 \pm 0.00194$ & $0.00756 \pm 0.00683$ & 0.02102 & 0.61466 & 0.28153 \\
\hline Mycobacterium & $0.00088 \pm 0.00058$ & $0 \pm 0$ & $0 \pm 0$ & 0.52842 & 1.00000 & 0.52013 \\
\hline Mycoplasma & $0.013 \pm 0.01151$ & $0 \pm 0$ & $0.00075 \pm 0.00075$ & 0.28651 & 1.00000 & 0.30851 \\
\hline Nesterenkonia & $0 \pm 0$ & $0 \pm 0$ & $0.00064 \pm 0.00064$ & 1.00000 & 1.00000 & 0.39968 \\
\hline $\begin{array}{l}\text { Nitrospiraceae_ } \\
\text { uncultured }\end{array}$ & $0 \pm 0$ & $0.00072 \pm 0.00072$ & $0 \pm 0$ & 0.38079 & 0.48016 & 1.00000 \\
\hline Ochrobactrum & $0.01515 \pm 0.00334$ & $0.00684 \pm 0.00496$ & $0.00507 \pm 0.00217$ & 0.17780 & 0.79573 & 0.01367 \\
\hline Odoribacter & $0.02862 \pm 0.01189$ & $0.0005 \pm 0.0005$ & $0.00304 \pm 0.00111$ & 0.02645 & 0.37696 & 0.03689 \\
\hline Opitutus & $0 \pm 0$ & $0.00072 \pm 0.00072$ & $0.00198 \pm 0.00094$ & 0.38079 & 0.62618 & 0.06384 \\
\hline Oscillibacter & $0.00134 \pm 0.00092$ & $1.91854 \pm 0.4873$ & $0.47583 \pm 0.15936$ & 0.00169 & 0.01063 & 0.00438 \\
\hline Oscillospira & $0.00043 \pm 0.00043$ & $0.1396 \pm 0.06182$ & $0.05487 \pm 0.0542$ & 0.03471 & 0.32838 & 0.34728 \\
\hline Ottowia & $0 \pm 0$ & $0 \pm 0$ & $0.00409 \pm 0.00409$ & 1.00000 & 0.34499 & 0.35432 \\
\hline Oxalobacter & $0 \pm 0$ & $0.04147 \pm 0.01443$ & $0 \pm 0$ & 0.00911 & 0.00915 & 1.00000 \\
\hline Paenisporosarcina & $0 \pm 0$ & $0 \pm 0$ & $0.00233 \pm 0.00233$ & 1.00000 & 0.12618 & 0.02552 \\
\hline Papillibacter & $0 \pm 0$ & $0.00885 \pm 0.00248$ & $0.01761 \pm 0.00523$ & 0.00235 & 0.14454 & 0.00181 \\
\hline Parabacteroides & $0.00087 \pm 0.00057$ & $0.29747 \pm 0.10585$ & $0.76933 \pm 0.24052$ & 0.01072 & 0.08878 & 0.00256 \\
\hline Pasteurella & $0.0104 \pm 0.00628$ & $0.00144 \pm 0.00144$ & $0.00442 \pm 0.00327$ & 0.17627 & 0.49073 & 0.49161 \\
\hline Paucimonas & $0 \pm 0$ & $0.00072 \pm 0.00072$ & $0 \pm 0$ & 0.38079 & 0.48016 & 1.00000 \\
\hline Pelomonas & $0.00266 \pm 0.00114$ & $0 \pm 0$ & $0.00058 \pm 0.00058$ & 0.08916 & 1.00000 & 0.25499 \\
\hline $\begin{array}{l}\text { Peptococcaceae_ } \\
\text { uncultured }\end{array}$ & $0 \pm 0$ & $0.11683 \pm 0.04023$ & $0.05492 \pm 0.01607$ & 0.00863 & 0.16894 & 0.00164 \\
\hline Peptococcus & $0 \pm 0$ & $0.01105 \pm 0.00382$ & $0.01071 \pm 0.00654$ & 0.00879 & 0.96040 & 0.10656 \\
\hline $\begin{array}{l}\text { Peptostreptococc } \\
\text { aceae_Incertae_Sedis }\end{array}$ & $9.05387 \pm 0.70459$ & $0.05952 \pm 0.03087$ & $0.11667 \pm 0.03346$ & 0.00000 & 0.22173 & 0.00000 \\
\hline Peptostreptococcus & $0.00048 \pm 0.00048$ & $0 \pm 0$ & $0 \pm 0$ & 1.00000 & 1.00000 & 1.00000 \\
\hline $\begin{array}{l}\text { Phascolarcto } \\
\text { bacterium }\end{array}$ & $4.99382 \pm 0.69833$ & $3.28502 \pm 1.54339$ & $0.532 \pm 0.40397$ & 0.36342 & 0.09938 & 0.00003 \\
\hline Phyllobacterium & $0.00188 \pm 0.00101$ & $0 \pm 0$ & $0 \pm 0$ & 0.30479 & 1.00000 & 0.15540 \\
\hline Pir4_lineage & $0.00044 \pm 0.00044$ & $0 \pm 0$ & $0 \pm 0$ & 1.00000 & 1.00000 & 1.00000 \\
\hline $\begin{array}{l}\text { Prevotellaceae_ } \\
\text { uncultured }\end{array}$ & $0 \pm 0$ & $0.64183 \pm 0.16969$ & $0.9912 \pm 0.41729$ & 0.00190 & 0.52234 & 0.02007 \\
\hline Prevotella & $0.00545 \pm 0.00269$ & $1.28652 \pm 0.75418$ & $0.93156 \pm 0.2499$ & 0.10279 & 0.72772 & 0.00083 \\
\hline Propionibacterium & $0.00362 \pm 0.00157$ & $0.004 \pm 0.00177$ & $0.00122 \pm 0.00079$ & 0.89485 & 0.16840 & 0.17603 \\
\hline Proteiniphilum & $0 \pm 0$ & $0 \pm 0$ & $0.00467 \pm 0.00467$ & 1.00000 & 0.34499 & 0.35432 \\
\hline Proteus & $0.03882 \pm 0.00637$ & $0 \pm 0$ & $0 \pm 0$ & 0.00021 & 1.00000 & 0.00002 \\
\hline Pseudomonas & $0 \pm 0$ & $0 \pm 0$ & $0.00376 \pm 0.00376$ & 1.00000 & 0.06348 & 0.01020 \\
\hline Pseudorhodoferax & $0.0008 \pm 0.0008$ & $0 \pm 0$ & $0 \pm 0$ & 0.52842 & 1.00000 & 0.52013 \\
\hline Pseudoxanthomonas & $0.00048 \pm 0.00048$ & $0.002 \pm 0.002$ & $0 \pm 0$ & 0.07310 & 0.05316 & 1.00000 \\
\hline RC9_gut_group & $0 \pm 0$ & $0.2138 \pm 0.0391$ & $0.25933 \pm 0.08393$ & 0.00037 & 0.69826 & 0.00352 \\
\hline Ramlibacter & $0 \pm 0$ & $0.00216 \pm 0.00216$ & $0 \pm 0$ & 0.05521 & 0.11070 & 1.00000 \\
\hline
\end{tabular}


Table III. Continued.

\begin{tabular}{|c|c|c|c|c|c|c|}
\hline \multirow[b]{2}{*}{ Phylum/Genus } & \multirow{2}{*}{$\begin{array}{c}\mathrm{HB}(\%) \\
\text { mean } \pm \mathrm{SD}\end{array}$} & \multirow{2}{*}{$\begin{array}{c}\mathrm{HF}(\%) \\
\text { mean } \pm \mathrm{SD}\end{array}$} & \multirow{2}{*}{$\begin{array}{c}\mathrm{Ctl}(\%) \\
\text { mean } \pm \mathrm{SD}\end{array}$} & \multicolumn{3}{|c|}{ P-value } \\
\hline & & & & HB vs. HF & HF vs. Ctl & $\mathrm{HB}$ vs. Ctl \\
\hline $\begin{array}{l}\text { Rhodobacteraceae_ } \\
\text { uncultured }\end{array}$ & $0.00044 \pm 0.00044$ & $0 \pm 0$ & $0 \pm 0$ & 1.00000 & 1.00000 & 1.00000 \\
\hline Rhodococcus & $0.00048 \pm 0.00048$ & $0 \pm 0$ & $0.00058 \pm 0.00058$ & 1.00000 & 1.00000 & 1.00000 \\
\hline Rhodocytophaga & $0.00086 \pm 0.00086$ & $0 \pm 0$ & $0 \pm 0$ & 0.52842 & 1.00000 & 0.52013 \\
\hline Rikenella & $0 \pm 0$ & $0 \pm 0$ & $0.00175 \pm 0.00175$ & 1.00000 & 0.25118 & 0.06384 \\
\hline Robinsoniella & $1.60965 \pm 0.60768$ & $0.00171 \pm 0.00171$ & $0.00075 \pm 0.00075$ & 0.01464 & 0.61074 & 0.01013 \\
\hline Roseburia & $0.00043 \pm 0.00043$ & $3.29178 \pm 0.50767$ & $0.72816 \pm 0.24779$ & 0.00015 & 0.00045 & 0.00493 \\
\hline Roseomonas & $0 \pm 0$ & $0.0005 \pm 0.0005$ & $0 \pm 0$ & 0.38079 & 0.48016 & 1.00000 \\
\hline Rothia & $0.00083 \pm 0.00055$ & $0.02233 \pm 0.00892$ & $0.01708 \pm 0.00747$ & 0.02418 & 0.72530 & 0.03511 \\
\hline $\begin{array}{l}\text { Ruminococcaceae_ } \\
\text { Incertae_Sedis }\end{array}$ & $0.53333 \pm 0.18071$ & $1.4356 \pm 0.21452$ & $0.98897 \pm 0.17647$ & 0.00379 & 0.12410 & 0.07627 \\
\hline $\begin{array}{l}\text { Ruminococcaceae_ } \\
\text { uncultured }\end{array}$ & $1.58302 \pm 0.3162$ & $13.47235 \pm 2.72614$ & $8.78594 \pm 2.20227$ & 0.00104 & 0.19671 & 0.00236 \\
\hline Ruminococcus & $0 \pm 0$ & $0.40738 \pm 0.06601$ & $0.70982 \pm 0.1478$ & 0.00019 & 0.07870 & 0.00011 \\
\hline Saccharopolyspora & $0.00048 \pm 0.00048$ & $0 \pm 0$ & $0 \pm 0$ & 1.00000 & 1.00000 & 1.00000 \\
\hline Salinicoccus & $0 \pm 0$ & $0 \pm 0$ & $0.00064 \pm 0.00064$ & 1.00000 & 1.00000 & 0.39968 \\
\hline $\begin{array}{l}\text { Saprospiraceae_ } \\
\text { uncultured }\end{array}$ & $0 \pm 0$ & $0.00144 \pm 0.00144$ & $0 \pm 0$ & 0.14500 & 0.23056 & 1.00000 \\
\hline Selenomonas & $0 \pm 0$ & $0.01814 \pm 0.01216$ & $0.01602 \pm 0.00427$ & 0.14733 & 0.88951 & 0.00082 \\
\hline $\begin{array}{l}\text { Sinobacteraceae_ } \\
\text { uncultured }\end{array}$ & $0 \pm 0$ & $0.00072 \pm 0.00072$ & $0.00075 \pm 0.00075$ & 0.38079 & 1.00000 & 0.39968 \\
\hline $\begin{array}{l}\text { Sphingobacteriaceae_ } \\
\text { uncultured }\end{array}$ & $0 \pm 0$ & $0 \pm 0$ & $0.00058 \pm 0.00058$ & 1.00000 & 1.00000 & 0.39968 \\
\hline Sphingobium & $0.00043 \pm 0.00043$ & $0 \pm 0$ & $0 \pm 0$ & 1.00000 & 1.00000 & 1.00000 \\
\hline Sphingomonas & $0.00253 \pm 0.00159$ & $0.00232 \pm 0.00149$ & $0 \pm 0$ & 1.00000 & 0.11070 & 0.08762 \\
\hline Sphingopyxis & $0.00049 \pm 0.00049$ & $0 \pm 0$ & $0 \pm 0$ & 1.00000 & 1.00000 & 1.00000 \\
\hline Staphylococcus & $0.00695 \pm 0.0036$ & $0.01002 \pm 0.00518$ & $0.0181 \pm 0.00654$ & 0.69869 & 0.41635 & 0.13924 \\
\hline Stenotrophomonas & $0.00402 \pm 0.00308$ & $0.00144 \pm 0.00144$ & $0.00637 \pm 0.00439$ & 0.53373 & 0.30516 & 0.73974 \\
\hline Streptococcus & $0.34317 \pm 0.15446$ & $0.85093 \pm 0.48484$ & $0.13616 \pm 0.05995$ & 0.37540 & 0.16071 & 0.22702 \\
\hline Streptomyces & $0 \pm 0$ & $0.00088 \pm 0.00088$ & $0 \pm 0$ & 0.38079 & 0.48016 & 1.00000 \\
\hline Subdoligranulum & $0 \pm 0$ & $0.0005 \pm 0.0005$ & $0 \pm 0$ & 0.38079 & 0.48016 & 1.00000 \\
\hline Sutterella & $0.0004 \pm 0.0004$ & $0.04729 \pm 0.01319$ & $0.00962 \pm 0.00278$ & 0.00254 & 0.01109 & 0.00213 \\
\hline $\begin{array}{l}\text { Syntrophobacter } \\
\text { aceae_uncultured }\end{array}$ & $0.0008 \pm 0.0008$ & $0 \pm 0$ & $0 \pm 0$ & 0.52842 & 1.00000 & 0.52013 \\
\hline Tetragenococcus & $0 \pm 0$ & $0 \pm 0$ & $0.00186 \pm 0.00131$ & 1.00000 & 0.25118 & 0.06384 \\
\hline Thalassolituus & $0.0004 \pm 0.0004$ & $0 \pm 0$ & $0 \pm 0$ & 1.00000 & 1.00000 & 1.00000 \\
\hline Thalassospira & $0.00048 \pm 0.00048$ & $0.01421 \pm 0.00381$ & $0.02303 \pm 0.00768$ & 0.00233 & 0.32926 & 0.00499 \\
\hline Thauera & $0 \pm 0$ & $0.0005 \pm 0.0005$ & $0.00175 \pm 0.00175$ & 0.38079 & 0.62618 & 0.06384 \\
\hline Thiobacillus & $0 \pm 0$ & $0 \pm 0$ & $0.00759 \pm 0.00759$ & 1.00000 & 0.34499 & 0.35432 \\
\hline $\begin{array}{l}\text { Thiotrichaceae_ } \\
\text { uncultured }\end{array}$ & $0 \pm 0$ & $0 \pm 0$ & $0.00075 \pm 0.00075$ & 1.00000 & 1.00000 & 0.39968 \\
\hline Treponema & $0.0013 \pm 0.0013$ & $0.89427 \pm 0.16598$ & $0.20351 \pm 0.11878$ & 0.00044 & 0.00327 & 0.09380 \\
\hline Trichococcus & $0 \pm 0$ & $0.00085 \pm 0.00085$ & $0 \pm 0$ & 0.38079 & 0.48016 & 1.00000 \\
\hline Turicibacter & $0.02804 \pm 0.01479$ & $0.00144 \pm 0.00144$ & $0.00824 \pm 0.0025$ & 0.08861 & 0.02923 & 0.20080 \\
\hline Veillonella & $0.00347 \pm 0.00128$ & $0.00594 \pm 0.0033$ & $0.00065 \pm 0.00065$ & 0.57852 & 0.13088 & 0.05251 \\
\hline Victivallis & $0 \pm 0$ & $0.0088 \pm 0.00401$ & $0.00389 \pm 0.00251$ & 0.04043 & 0.32513 & 0.00408 \\
\hline $\begin{array}{l}\text { Xanthobacteraceae_ } \\
\text { uncultured }\end{array}$ & $0 \pm 0$ & $0 \pm 0$ & $0.00065 \pm 0.00065$ & 1.00000 & 1.00000 & 0.39968 \\
\hline Xylanibacter & $0 \pm 0$ & $0.22435 \pm 0.186$ & $0.01461 \pm 0.00458$ & 0.25461 & 0.27539 & 0.00258 \\
\hline
\end{tabular}


Table III. Continued.

\begin{tabular}{|c|c|c|c|c|c|c|}
\hline \multirow[b]{2}{*}{ Phylum/Genus } & \multirow{2}{*}{$\begin{array}{c}\mathrm{HB}(\%) \\
\text { mean } \pm \mathrm{SD}\end{array}$} & \multirow{2}{*}{$\begin{array}{c}\mathrm{HF}(\%) \\
\text { mean } \pm \mathrm{SD}\end{array}$} & \multirow{2}{*}{$\begin{array}{c}\mathrm{Ctl}(\%) \\
\text { mean } \pm \mathrm{SD}\end{array}$} & \multicolumn{3}{|c|}{ P-value } \\
\hline & & & & HB vs. HF & $\mathrm{HF}$ vs. $\mathrm{Ctl}$ & $\mathrm{HB}$ vs. $\mathrm{Ctl}$ \\
\hline $\begin{array}{l}\text { vadinBC27_waste } \\
\text { water-sludge_group }\end{array}$ & $0 \pm 0$ & $0 \pm 0$ & $0.00075 \pm 0.00075$ & 1.00000 & 1.00000 & 0.39968 \\
\hline
\end{tabular}

Difference in the relative abundance of phylotypes defined at 97\%-ID in rats in the Ctl, HF and HB groups. Ctl, normal diet; HF, HFD; HB, HFD supplemented with berberine for 6 weeks; HFD, high-fat diet.

gut microbiome changed along the first ordination axis, which accounted for $72.8 \%$ of total variance (Fig. 9F).

Berberine appeared to significantly alter the abundance of 34 genera, 14 of which were increased, whereas the remaining 20 were decreased or eliminated (Table IV). Notably, the genus Akkermansia of the Verrucomicrobia phylum could not be detected in the HF group however, it was detected in the HB group. The genera Collinsella, Prevotellaceae_uncultured, Christensenellaceae_uncultured and Ruminococcus were detected in the HF group however, not in the HB group. Furthermore, the relative abundance of 21 genera appeared significantly increased in the HF group compared with in the control group. Among these, treatment with berberine significantly decreased the abundance of 11 genera, including Roseburia, Allobaculum, Oscillibacter, Faecalibacterium, Prevotella and Desulfovibrio. A total of 3 genera (Coprococcus, Collinsella and Blautia) remained unaffected by the HFD, however, they were significantly decreased following berberine supplementation. In addition, 10 genera appeared significantly decreased in the HFD-fed group, of which 4 were significantly increased following treatment with berberine, including Erysipelotrichaceae_Incertae_Sedis, Peptostreptococcaceae_ Incertae_Sedis and Escherichia-Shigella. Furthermore, the genera Fusobacterium, Anaerostipes, Bacteroides and Phascolarctobacterium were also significantly increased by treatment with berberine.

In order to identify the specific genera of intestinal bacteria that could be associated with the beneficial effects of berberine, Spearman's correlation analysis was performed between the 34 genera whose distribution appeared to be altered following berberine supplementation and a number of physiological parameters. The analyses revealed that weight, glucose intolerance, FITC-dextran area and L-cell number were correlated with the abundance of several genera (Table V).

\section{Discussion}

It has previously been demonstrated that berberine participates in the regulation of glucose and lipid metabolism through targeting gut microbiota; however, the implication of its modulatory effects on gut microbiota in metabolic disorders has not yet been examined. Growing evidence has suggested that the gut microbiome contributes to the systemic low-grade inflammation that is characteristic of metabolic disorders. LPS from intestinal bacteria can leak into the circulation through the damaged intestinal mucosa (15), where it can cause metabolic endotoxemia and the production of proinflammatory cytokines, thereby contributing to insulin resistance and related metabolic disorders $(26,27)$. Plasma LPS levels are a direct biomarker of systemic inflammation. The present study revealed that berberine can significantly decrease plasma LPS levels, which is in accordance with previous results reporting that berberine can significantly prevent HFD-induced systemic inflammation by decreasing serum LPS-binding protein levels (14). Since macrophage infiltration and oxidative stress in adipose tissue participate in inflammation and insulin resistance (28-30), a number of inflammatory and oxidative stress factors were investigated in order to evaluate the role of berberine in systemic inflammation. Berberine appeared to reduce the HFD-induced mRNA expression levels of markers of inflammation (IL-1 $\beta$ and PAI-1), oxidative stress (NADPHox and STAMP-2) and macrophage infiltration (MCP-1 and F4/80) in visceral adipose tissue. Berberine has previously been reported to downregulate the expression of the proinflammatory cytokines TNF- $\alpha$, IL-1, IL- 6 and MCP-1 in white adipose tissue from $\mathrm{db} / \mathrm{db}$ mice (31). Furthermore, the correlations that were revealed in the present study between these markers and plasma LPS levels further support the hypothesis that berberine can improve the endotoxemia-induced systemic inflammation in HFD-fed rats.

The present results suggested that the beneficial effect of berberine on endotoxemia is unlikely to be a result of a decrease in Gram-negative bacteria (Table III), thus indicating that berberine may reduce endotoxemia through reducing intestinal permeability. Alterations in intestinal permeability have previously been associated with alterations in the expression, localization and distribution of tight junction proteins, including claudins, ZO-1 and occludin (32). It has also been suggested that berberine may directly affect the expression of tight junction proteins. Amasheh et al (33) reported that in HT-29/B6 cells, berberine increased the mRNA expression levels of claudin-1, however, not claudin-2. In a rat model of LPS-induced injury, berberine administration following LPS injection did not appear to ameliorate the expression and distribution of the tight junction proteins claudin-1, claudin-4, ZO-1 and occludin, and had no effect on intestinal permeability. However, pretreatment with berberine for 7 days was reported to partially attenuate the LPS-induced destruction and redistribution of tight junction proteins (34). Considering the pharmacokinetic features of berberine, it may be hypothesized 


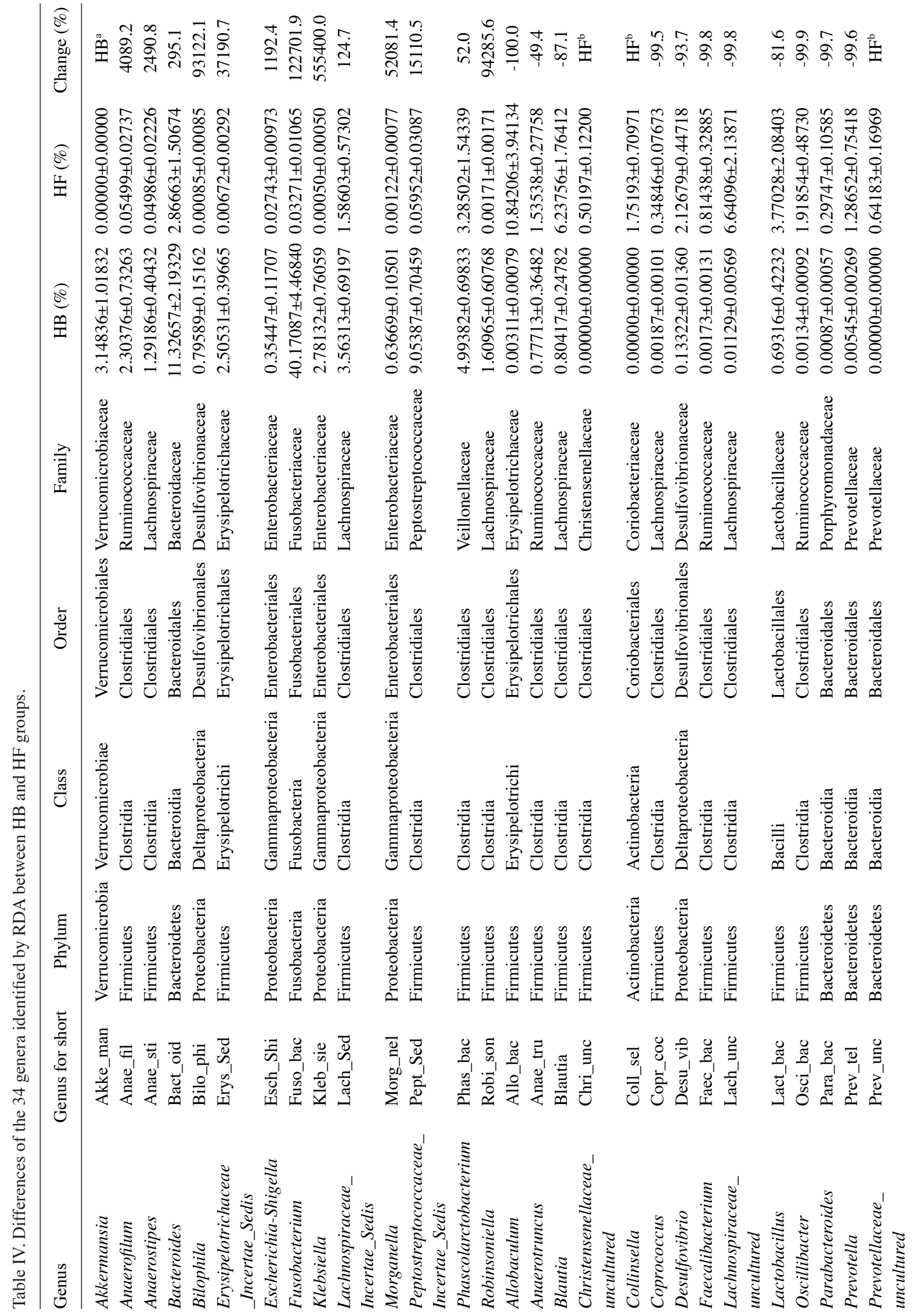


that berberine required a longer time-frame to reach its effective concentration. The present study demonstrated that berberine supplementation for 6 weeks significantly increased the expression of claudin-1 and ZO-1 in the proximal colon of HFD-induced obese rats. In addition, berberine appeared to partially restore the intestinal distribution of claudin- 1 and claudin-2. These results suggested that berberine, through increasing the expression and restoring the distribution of tight junction proteins may contribute to the restoration of intestinal epithelial integrity.

In addition to its direct effects on the expression of tight junction proteins, berberine has been reported to indirectly restore gut permeability, through modulating gut microbiota. Previous studies have suggested that gut microbiota may regulate epithelial permeability $(32,35,36)$. SCFAs, which are the main metabolic products of bacterial fermentation, have been suggested to improve the function of the gut barrier by promoting epithelial cell growth and facilitating tight junction formation $(37,38)$. Zhang et al (14) reported that berberine, through increasing the SCFA-producing genera Blautia and Allobaculum, enhanced intestinal integrity and thus antagonized obesity. However, the results of the present study revealed that berberine significantly decreased Blautia and Allobaculum bacteria, although intestinal permeability was improved. The present results agree with a previous report by Xie et al (2) demonstrating that berberine exerted anti-obesity effects partly by decreasing the degradation of dietary polysaccharides and fecal SCFA production to inhibit energy harvest. Previous studies have suggested that the relationship between fecal SCFAs and the regulation of host metabolism is important and complex $(2,16)$. In contrast to the model used by Zhang et al (14), the present study evaluated the effect of berberine in rats maintained on a HFD for 14 weeks, resembling the clinical situation. However, future studies are required to investigate the role of berberine on SCFA-producing genera of intestinal bacteria.

In the present study, a Spearman's correlation analysis revealed a negative correlation between intestinal permeability and the abundance of the Phascolarctobacterium and Collinsella genera, and berberine supplementation significantly increased the abundance of the genus Phascolarctobacterium. Intestinal permeability appeared positively correlated with the abundance of the Anaerotruncus and Oscillibacter genera (Table V). The present findings indicated that Phascolarctobacterium, Anaerotruncus and Oscillibacter may be solely responsible for the beneficial effects of berberine on intestinal permeability. A significant 10-fold decrease in the genus Oscillibacter was observed in berberine-treated HFD-fed rats. It has previously been reported that a HFD significantly increased the abundance of Oscillibacter, which was negatively correlated with transepithelial resistance and ZO-1 mRNA expression levels in the proximal colon (39). In accordance with the previous study, the present results suggested that berberine may increase ZO-1 mRNA expression levels and intestinal permeability, possibly by inhibiting Oscillibacter abundance. In addition, the genus Akkermansia was reported to be present exclusively in berberine-treated rats. Previous studies have suggested that Akkermansia muciniphila may restore the thickness of the intestinal mucosa and counteract HFD-induced mucosal barrier dysfunction in the colon (40), whereas it has been suggested 
式

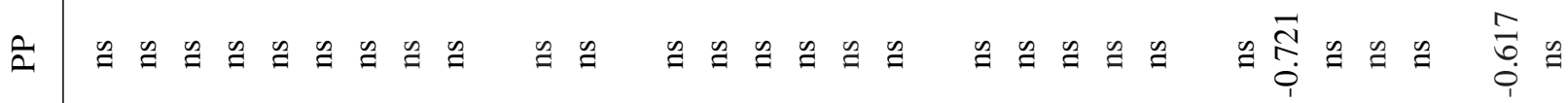

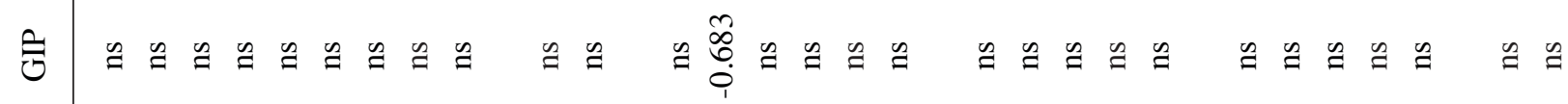
岂 岇

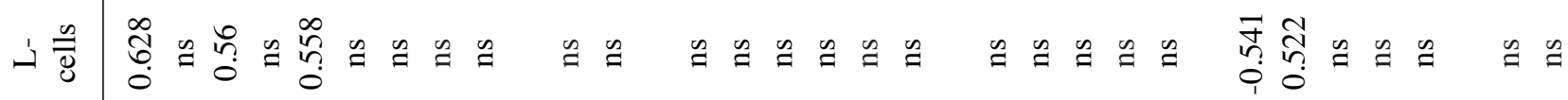

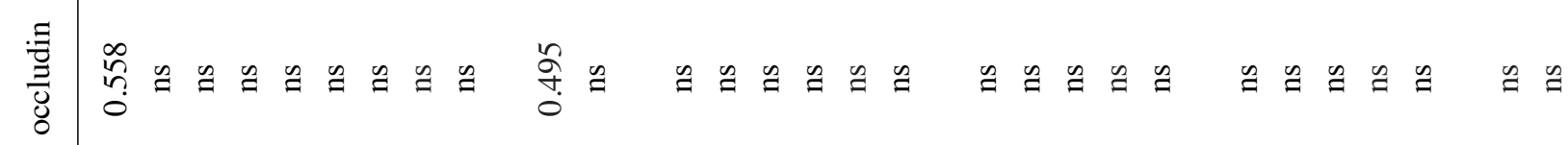

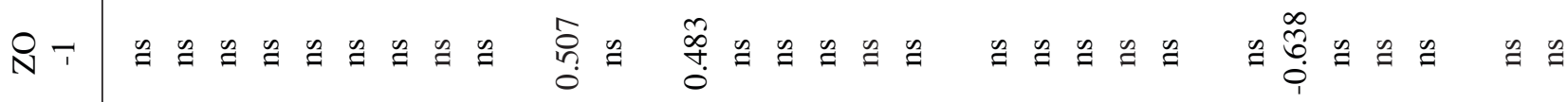
壭 辛

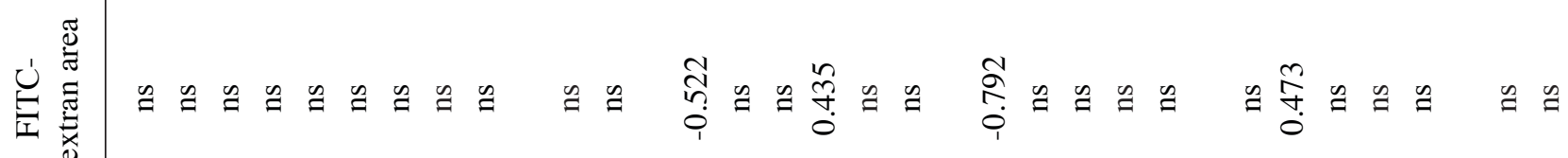

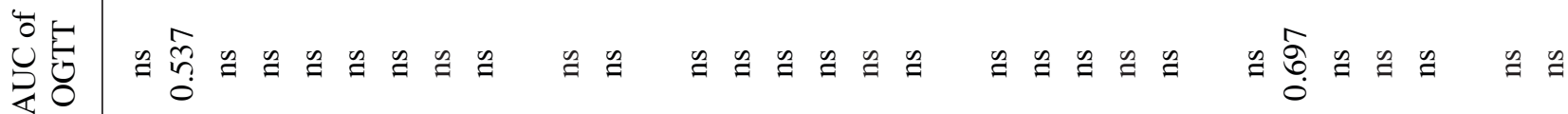

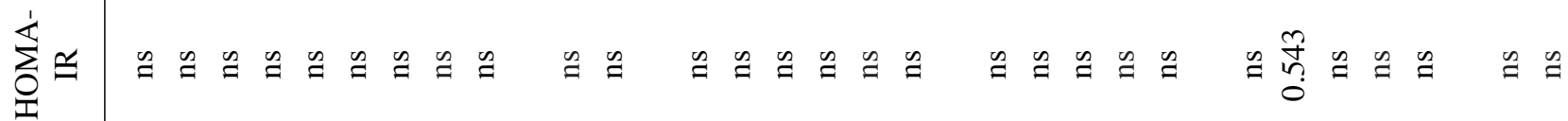

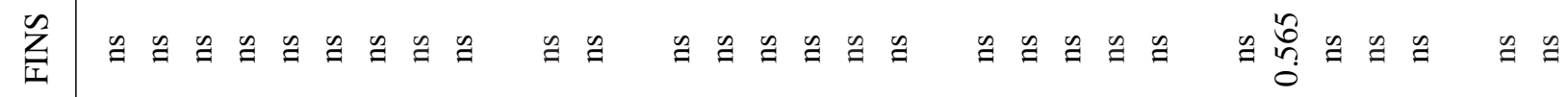

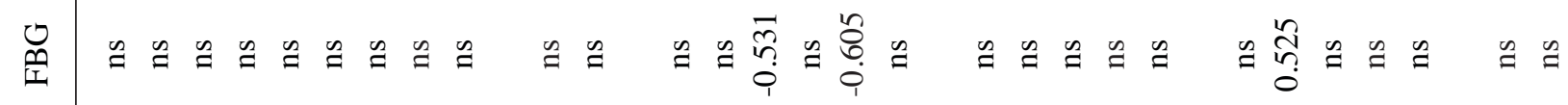

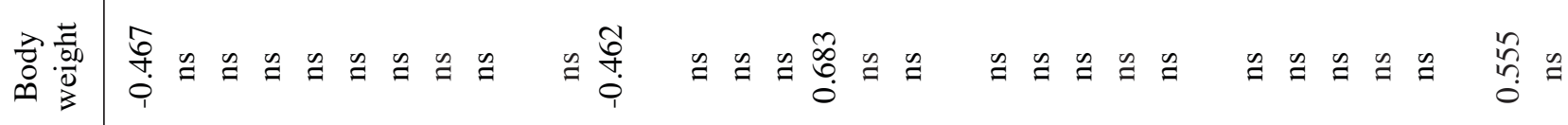

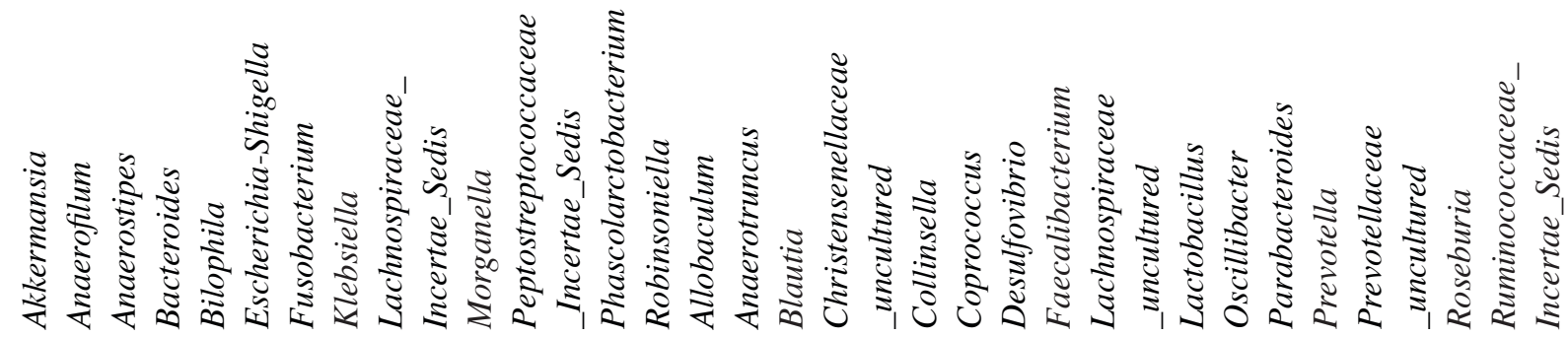


that this species may hold a key role in gut barrier function and metabolic inflammation (41). However, a significant correlation between the genus Akkermansia and intestinal permeability was not observed in the present study. Further work is required to explore the putative relationship between the abundance of Akkermansia bacteria and the integrity of the gut barrier.

The modulation of gut hormone levels by berberine has been reported to serve an important role in improving energy homeostasis. Previous studies have revealed that berberine increased the number of L-cells and the mRNA expression levels of proglucagon in the ileum, whereas it promoted GLP-1 secretion in normal and diabetic rats $(9,10)$. In the present study, berberine significantly increased the portal plasma levels of GLP-1 and GLP-2, whereas it also increased the number of L-cells and the mRNA expression levels of proglucagon in the proximal colon. Multiple lines of evidence have linked gut microbiota with the enteroendocrine system, whereas SCFAs are the most studied among gut microbial metabolites (42). In the present study, Spearman's correlation analysis revealed that L-cell numbers were positively correlated with the abundance of 4 genera (Akkermansia, Anaerostipes, Bilophila and Oscillibacter) and negatively correlated with the abundance of the genus Lactobacillus (Table V). Previous studies reported a positive correlation between the abundance of bacteria of the Akkermansia genus and L-cell numbers in the colon, whereas Akkermansia muciniphila administration significantly increased GLP-1 release from colonic L-cells $(43,44)$. Sequencing results of the present study revealed that the abundance of Akkermansia was significantly increased by berberine, although the correlation between Akkermansia and GLP-1 levels was not significant. Based on previous research that correlated the abundance of 10 genera with L-cell numbers (43), the present study confirmed that berberine increased the abundance of the genus Akkermansia and decreased the abundance of the genus Lactobacillus, which appeared to be associated with the increase in L-cell numbers and enteroendocrine peptide secretion from L-cells. In addition, Spearman's correlation analysis revealed plasma GIP levels to be negatively correlated with the abundance of the Robinsoniella genus.

The present study suggested that the wide shift in the gut microbiota composition induced by berberine may attenuate insulin resistance and related metabolic disorders in HFD-fed rats via several pathways. Firstly, berberine supplementation alleviated metabolic endotoxemia and subsequent systemic inflammation, via restoring the integrity of the gut barrier through increasing the expression and restoring the distribution of tight junction proteins. Furthermore, berberine modulated the plasma levels of gut hormones involved in glucose regulation and energy homeostasis, possibly via interfering with the composition of the gut microbiome. In conclusion, the present results suggested that berberine may be a potential therapeutic strategy for the treatment of obesity and insulin resistance. However, further study is required to delineate the mechanism of action of berberine.

\section{Acknowledgements}

This study was supported by the National Natural Science Foundation of China (grant no. 81170738). 


\section{References}

1. Zhang Y, Li X, Zou D, Liu W, Yang J, Zhu N, Huo L, Wang M, Hong J, Wu P, et al: Treatment of type 2 diabetes and dyslipidemia with the natural plant alkaloid berberine. J Clin Endocrinol Metab 93: 2559-2565,2008.

2. Xie W, Gu D, Li J, Cui K and Zhang Y: Effects and action mechanisms of berberine and Rhizoma coptidis on gut microbes and obesity in high-fat diet-fed C57BL/6J mice. PLoS One 6: e24520, 2011.

3. Gomes AP, Duarte FV, Nunes P, Hubbard BP, Teodoro JS, Varela AT, Jones JG, Sinclair DA, Palmeira CM and Rolo AP: Berberine protects against high fat diet-induced dysfunction in muscle mitochondria by inducing SIRT1-dependent mitochondrial biogenesis. Biochim Biophys Acta 1822: 185-195, 2012.

4. Lee YS, Kim WS, Kim KH, Yoon MJ, Cho HJ, Shen Y, Ye JM, Lee $\mathrm{CH}$, Oh WK, Kim CT, et al: Berberine, a natural plant product, activates AMP-activated protein kinase with beneficial metabolic effects in diabetic and insulin-resistant states. Diabetes 55: 2256-2264, 2006.

5. Liu L, Yu YL, Yang JS, Li Y, Liu YW, Liang Y, Liu XD, Xie L and Wang GJ: Berberine suppresses intestinal disaccharidases with beneficial metabolic effects in diabetic states, evidences from in vivo and in vitro study. Naunyn Schmiedebergs Arch Pharmacol 381: 371-381, 2010.

6. Pan GY, Huang ZJ, Wang GJ, Fawcett JP, Liu XD, Zhao XC, Sun JG and Xie YY: The antihyperglycaemic activity of berberine arises from a decrease of glucose absorption. Planta Med 69: 632-636, 2003

7. Kong W, Wei J, Abidi P, Lin M, Inaba S, Li C, Wang Y, Wang Z, $\mathrm{Si} \mathrm{S}, \mathrm{Pan} \mathrm{H}$, et al: Berberine is a novel cholesterol-lowering drug working through a unique mechanism distinct from statins. Nat Med 10: 1344-1351, 2004.

8. Wang Y, Yi X, Ghanam K, Zhang S, Zhao T and Zhu X: Berberine decreases cholesterol levels in rats through multiple mechanisms, including inhibition of cholesterol absorption. Metabolism 63: $1167-1177,2014$

9. Lu SS, Yu YL, Zhu HJ, Liu XD, Liu L, Liu YW, Wang P, Xie L and Wang GJ: Berberine promotes glucagon-like peptide-1 (7-36) amide secretion in streptozotocin-induced diabetic rats. J Endocrinol 200: 159-165, 2009.

10. Yu Y,Liu L, Wang X,Liu X,Liu X, Xie Land Wang G: Modulation of glucagon-like peptide-1 release by berberine: In vivo and in vitro studies. Biochem Pharmacol 79: 1000-1006, 2010.

11. Liu YT, Hao HP, Xie HG, Lai L, Wang Q, Liu CX and Wang GJ: Extensive intestinal first-pass elimination and predominant hepatic distribution of berberine explain its low plasma levels in rats. Drug Metab Dispos 38: 1779-1784, 2010.

12. Chen W, Miao YQ, Fan DJ, Yang SS, Lin X, Meng LK and Tang X Bioavailability study of berberine and the enhancing effects of TPGS on intestinal absorption in rats. AAPS PharmSciTech 12: 705-711, 2011

13. Aronsson L, Huang Y, Parini P, Korach-André M, Håkansson J, Gustafsson JÅ, Pettersson S, Arulampalam V and Rafter J: Decreased fat storage by Lactobacillus paracasei is associated with increased levels of angiopoietin-like 4 protein (ANGPTL4). PLoS One 5: e13087, 2010.

14. Zhang X, Zhao Y, Zhang M, Pang X, Xu J, Kang C, Li M, Zhang C, Zhang Z, Zhang Y, et al: Structural changes of gut microbiota during berberine-mediated prevention of obesity and insulin resistance in high-fat diet-fed rats. PLoS One 7: e42529, 2012.

15. Cani PD, Possemiers S, Van de Wiele T, Guiot Y, Everard A, Rottier O, Geurts L, Naslain D, Neyrinck A, Lambert DM, et al: Changes in gut microbiota control inflammation in obese mice through a mechanism involving GLP-2-driven improvement of gut permeability. Gut 58: 1091-1103, 2009.

16. Cani PD, Lecourt E, Dewulf EM, Sohet FM, Pachikian BD, Naslain D, De Backer F, Neyrinck AM and Delzenne NM: Gut microbiota fermentation of prebiotics increases satietogenic and incretin gut peptide production with consequences for appetite sensation and glucose response after a meal. Am J Clin Nutr 90 1236-1243, 2009.

17. Cani PD, Neyrinck AM, Maton $\mathrm{N}$ and Delzenne NM Oligofructose promotes satiety in rats fed a high-fat diet: Involvement of glucagon-like peptide-1. Obes Res 13: 1000-1007, 2005.

18. Cani PD, Hoste S, Guiot Y and Delzenne NM: Dietary non-digestible carbohydrates promote L-cell differentiation in the proximal colon of rats. Br J Nutr 98: 32-37, 2007.
19. Tazoe H, Otomo Y, Karaki S, Kato I, Fukami Y, Terasaki M and Kuwahara A: Expression of short-chain fatty acid receptor GPR41 in the human colon. Biomed Res 30: 149-156, 2009.

20. Tolhurst G, Heffron H, Lam YS, Parker HE, Habib AM, Diakogiannaki E, Cameron J, Grosse J, Reimann F and Gribble FM: Short-chain fatty acids stimulate glucagon-like peptide-1 secretion via the G-protein-coupled receptor FFAR2. Diabetes 61: 364-371, 2012.

21. des Rieux A, Pourcelle V, Cani PD, Marchand-Brynaert J and Préat V: Targeted nanoparticles with novel non-peptidic ligands for oral delivery. Adv Drug Deliv Rev 65: 833-844, 2013.

22. Psichas A, Sleeth ML, Murphy KG, Brooks L, Bewick GA, Hanyaloglu AC, Ghatei MA, Bloom SR and Frost G: The short chain fatty acid propionate stimulates GLP-1 and PYY secretion via free fatty acid receptor 2 in rodents. Int J Obes (Lond) 39: 424-429, 2015.

23. Feng Y, Li Y, Chen C, Lin X, Yang Y, Cai H, Lv Z, Cao M, Li K, $\mathrm{Xu}$, et al: Inhibiting roles of berberine in gut movement of rodents are related to activation of the endogenous opioid system. Phytother Res 27: 1564-1571, 2013.

24. Shan CY, Yang JH, Kong Y, Wang XY, Zheng MY, Xu YG, Wang Y, Ren HZ, Chang BC and Chen LM: Alteration of the intestinal barrier and GLP2 secretion in Berberine-treated type 2 diabetic rats. J Endocrinol 218: 255-262, 2013.

25. Livak KJ and Schmittgen TD: Analysis of relative gene expression data using real-time quantitative PCR and the 2(-Delta Delta C(T)) method. Methods 25: 402-408, 2001.

26. Kim KA, Gu W, Lee IA, Joh EH and Kim DH: High fat diet-induced gut microbiota exacerbates inflammation and obesity in mice via the TLR4 signaling pathway. PLoS One 7: e47713, 2012

27. Glass CK and Olefsky JM: Inflammation and lipid signaling in the etiology of insulin resistance. Cell Metab 15: 635-645, 2012.

28. Furukawa S, Fujita T, Shimabukuro M, Iwaki M, Yamada Y, Nakajima Y, Nakayama O, Makishima M, Matsuda M and Shimomura I: Increased oxidative stress in obesity and its impact on metabolic syndrome. J Clin Invest 114: 1752-1761, 2004.

29. Shoelson SE, Lee J and Goldfine AB: Inflammation and insulin resistance. J Clin Invest 116: 1793-1801, 2006.

30. Shoelson SE, Herrero L and Naaz A: Obesity, inflammation and insulin resistance. Gastroenterology 132: 2169-2180, 2007.

31. Jeong HW, Hsu KC, Lee JW, Ham M, Huh JY, Shin HJ, Kim WS and Kim JB: Berberine suppresses proinflammatory responses through AMPK activation in macrophages. Am J Physiol Endocrinol Metab 296: E955-E964, 2009.

32. Everard A and Cani PD: Diabetes, obesity and gut microbiota. Best Pract Res Clin Gastroenterol 27: 73-83, 2013.

33. Amasheh M, Fromm A, Krug SM, Amasheh S, Andres S, Zeitz M, Fromm M and Schulzke JD: TNFalpha-induced and berberine-antagonized tight junction barrier impairment via tyrosine kinase, Akt and NFkappaB signaling. J Cell Sci 123: 4145-4155, 2010 .

34. Ma JY, Feng R, Tan XS, Ma C, Shou JW, Fu J, Huang M, He CY, Chen SN, Zhao ZX, et al: Excretion of berberine and its metabolites in oral administration in rats. J Pharm Sci 102: 4181-4192, 2013.

35. Yu LC, Wang JT, Wei SC and Ni YH: Host-microbial interactions and regulation of intestinal epithelial barrier function: From physiology to pathology. World J Gastrointest Pathophysiol 3: 27-43, 2012.

36. Greiner T and Bäckhed F: Effects of the gut microbiota on obesity and glucose homeostasis. Trends Endocrinol Metab 22: $117-123,2011$.

37. Ichikawa $\mathrm{H}$ and Sakata T: Stimulation of epithelial cell proliferation of isolated distal colon of rats by continuous colonic infusion of ammonia or short-chain fatty acids is nonadditive. J Nutr 128 : 843-847, 1998

38. Peng L, Li ZR, Green RS, Holzman IR and Lin J: Butyrate enhances the intestinal barrier by facilitating tight junction assembly via activation of AMP-activated protein kinase in Caco-2 cell monolayers. J Nutr 139: 1619-1625, 2009.

39. Lam Y, Ha CW, Campbell CR, Mitchell AJ, Dinudom A, Oscarsson J, Cook DI, Hunt NH, Caterson ID, Holmes AJ, et al: Increased gut permeability and microbiota change associate with mesenteric fat inflammation and metabolic dysfunction in diet-induced obese mice. PLoS One 7: e34233, 2012. 
40. Everard A, Belzer C, Geurts L, Ouwerkerk JP, Druart C, Bindels LB, Guiot Y, Derrien M, Muccioli GG, Delzenne NM, et al: Cross-talk between Akkermansia muciniphila and intestinal epithelium controls diet-induced obesity. Proc Natl Acad Sci USA 110: 9066-9071, 2013.

41. Anhê FF, Roy D, Pilon G, Dudonné S, Matamoros S, Varin TV, Garofalo C, Moine Q, Desjardins Y, Levy E, et al: A polyphenol-rich cranberry extract protects from diet-induced obesity, insulin resistance and intestinal inflammation in association with increased Akkermansia spp. population in the gut microbiota of mice. Gut 64: 872-883, 2015.

42. Cani PD, Everard A and Duparc T: Gut microbiota, enteroendocrine functions and metabolism. Curr Opin Pharmacol 13 935-940, 2013.
43. Everard A, Lazarevic V, Derrien M, Girard M, Muccioli GG, Neyrinck AM, Possemiers S, Van Holle A, François P, de Vos WM, et al: Responses of gut microbiota and glucose and lipid metabolism to prebiotics in genetic obese and diet-induced leptin-resistant mice. Diabetes 60: 2775-2786, 2011.

44. Hansen KB, Rosenkilde MM, Knop FK, Wellner N, Diep TA, Rehfeld JF, Andersen UB, Holst JJ and Hansen HS: 2-Oleoyl glycerol is a GPR119 agonist and signals GLP-1 release in humans. J Clin Endocrinol Metab 96: E1409-E1417, 2011. 